\title{
SITA STECKEL
}

\section{Differenzierung jenseits der Moderne}

Eine Debatte zu mittelalterlicher Religion und moderner Differenzierungstheorie*

1. Mittelaltergeschichte und soziologische Differenzierungstheorie: Ausgangspunkte einer Debatte, S. m. - 2. Modernen und ihr Mittelalter: Von Burckhardt über Weber zum 'Rise of the West', S.

3. Alternative Erzählungen: Sakralisierung und Desakralisierung, Diversifizierung und Verflechtung auf dem religiösen Feld, S. ana. - 4. Historische Rahmenannahmen und Verlaufsprozesse: Bourdieu versus Luhmann, S. mqu. - 5. Schlussüberlegungen: Konjunkturen des Religiösen, S.

\section{MITTELALTERGESCHICHTE UND SOZIOLOGISCHE DIFFERENZIERUNGSTHEORIE: AUSGANGSPUNKTE EINER DEBATTE}

In seiner 1991 erschienenen Rezension des dritten Bandes von „Gesellschaftsstruktur und Semantik“ schalt der Mittelalterhistoriker Otto Gerhard Oexle den Soziologen Niklas Luhmann wegen seines allzu einseitigen Mittelalterbildes ${ }^{1}$. Luhmann verwahrte sich mit mehreren Argumenten dagegen. Er wies zunächst darauf hin, dass er in dem Band sowieso zumeist über die Frühe Neuzeit schreibe, was bereits andeutet, dass sein Mittelalter hauptsächlich ein Gegenbild für spätere Entwicklungen war. Doch angesichts von Luhmanns Kategorisierung des Mittelalters als stratifizierte Gesellschaft wies Oexle auch auf diverse Phänomene der mittelalterlichen Politik, des Rechts und der Wissenschaft hin, die bereits als Anzeichen einer funktional differenzierten Gesellschaft erschienen.

\footnotetext{
* Dieser Beitrag entstand im Kontext der Arbeitsplattform „Differenzierung und Entdifferenzierung“ des Exzellenzclusters „Religion und Politik in den Kulturen der Vormoderne und der Moderne“, s. Anm. 4. Für die Initiative und die vielen Anregungen, die sich im Laufe der dortigen Diskussion ergaben, möchte ich mich herzlich bedanken, in vorderster Linie bei Detlef Pollack. Für die Initiative zur gemeinsamen Publikation der vorliegenden Beiträge danke ich zudem Gerd Althoff und Wolfram Drews. Ein weiterer Dank gilt den Mitgliedern der Arbeitsplattform, besonders Christel Gärtner, sowie der Cluster-Arbeitsgruppe „Grenzarbeiten“ und Astrid Reuter. Weitere Anregungen, insbesondere zu den globalgeschichtlichen Dimensionen des Themas, verdanke ich den Teilnehmern eines Workshops, den ich unter dem Titel „The Making of Religion? Re-Describing Religious Change in Pre-Modern Europe“ im April 2011 veranstaltet hatte, besonders Antje Flüchter, Frank Rexroth und Alexandra Walsham. Für weitere Hinweise danke ich Christina Brauner, Andreas Pietsch und Christoph F. Weber.

1 OTtO Gerhard OexLe, Luhmanns Mittelalter, in: Rechtshistorisches Journal 10, 1991, S. 53-66, mit Bezug auf NiKLas LuhmanN, Gesellschaftsstruktur und Semantik. Studien zur Wissenssoziologie der modernen Gesellschaft, 3, Frankfurt a. M. 1989.
} 
Diesem mittelalterlichen Präkursorismus nahm Luhmann einfach den Wind aus den Segeln: Er räumte das Vorhandensein dieser Tendenzen umgehend ein, verwahrte sich sogar leicht empört gegen den Vorwurf, angeblich nicht um den „Phänomenreichtum des Mittelalters“ zu wissen. Er hielt aber Reduktion für nötig, ja formulierte ausdrücklich: „nur kommt man, wissenschaftlich gesehen, nicht sehr weit, wenn man versucht, all dies unter dem Begriff des Mittelalters zusammenzufassen." 2 Der Vielfalt des Mittelalters rückte Luhmann also mit radikaler Komplexitätsreduktion zu Leibe.

Der Schlagabtausch illustriert, dass Geschichtswissenschaft und Soziologie sich schon seit Längerem gern kritisch rezipieren. Genauso wird aber deutlich, dass die jeweiligen Themen und Interessen trotz unterschiedlicher Blickwinkel äußerst nah beieinanderliegen. Gerade Theorien über die Moderne kommen zumeist nicht ohne ein Mittelalter aus, sei es auch nur als ein Gegenbild ${ }^{3}$. Die Form gesellschaftlicher Differenzierung, die Luhmann für die Moderne ansetzt - die primär funktional differenzierte Gesellschaft - lässt sich nicht gut ohne den mittelalterlichen Kontrast einer stratifizierten, nach Ständen gegliederten Gesellschaft erklären. Umgekehrt braucht die Mediävistik Rahmenannahmen zu übergeordneten historischen Prozessen, um ihrer quellengestützten Arbeit Verlaufsannahmen unterlegen und Relevanz zuschreiben $\mathrm{zu}$ können. Soziologie und Mittelaltergeschichte bleiben somit aufeinander angewiesen.

Dieser Austausch bleibt, bei allem Dissens im Detail, äußerst anregend und soll auch im vorliegenden Text fortgesetzt werden. Er entstand ursprünglich als Kommentar zu Detlef Pollacks Aufsatz „Die Genese der westlichen Moderne. Religiöse Bedingungen der Emergenz funktionaler Differenzierung im Mittelalter", der gemeinsam mit einem weiteren Kommentar von Gerd Althoff in diesem Band veröffentlicht wird ${ }^{4}$. Knapp gesagt, kehrt Detlef Pollack darin zu der schon von

2 Vgl. NikLas LuHmanN, Mein Mittelalter, in: Rechthistorisches Journal 10, 1991, S. 66-70, beide Zitate S. 69.

3 Vgl. zum Mittelalterbild der Moderne GERD ALthoff (Hg.), Die Deutschen und ihr Mittelalter Themen und Funktionen moderner Geschichtsbilder vom Mittelalter, Darmstadt 1992, darin besonders OtTo Gerhard OexLe, Das entzweite Mittelalter, S. 7-28, hier S. 12. Peter SEgL (Hg.), Mittelalter und Moderne. Entdeckung und Rekonstruktion der mittelalterlichen Welt. Kongressakten des 6. Symposiums des Mediävistenverbandes in Bayreuth 1995, Sigmaringen 1997, besonders ОтTО Gerhard OexLe, Die Moderne und ihr Mittelalter, ebd. S. 307-364; Frank ReXroth (Hg.), Meistererzählungen vom Mittelalter: Epochenimaginationen und Verlaufsmuster in der Praxis mediävistischer Disziplinen (Historische Zeitschrift. Beiheft NF 46) München 2007; DERS., Das Mittelalter und die Moderne in den Meistererzählungen der historischen Wissenschaften, in: WOlfGANG HAUbrichs - MANFRED ENGEL (Hgg.), Erfindung des Mittelalters (= Zeitschrift für Literaturwissenschaft und Linguistik 151) Stuttgart 2008, S. 12-31; zuletzt THOMAS MARTIN BUCK NicOla BRAUCH (Hgg.), Das Mittelalter zwischen Vorstellung und Wirklichkeit. Probleme, Perspektiven und Anstöße für die Unterrichtspraxis, Münster 2011; PATRICK J. GEARY - GÁBOR KLANICZAY (Hgg.), Manufacturing Middle Ages: Entangled History of Medievalism in NineteenthCentury Europe, Leiden u. a. 2013.

${ }_{4}$ Vgl. DeTleF POLLACK, Die Genese der westlichen Moderne. Religiöse Bedingungen der Emergenz funktionaler Differenzierung im Mittelalter, sowie GERD ALTHOFF, Differenzierung zwischen Kirche 
Luhmann und Oexle diskutierten makrotheoretischen Frage zurück: Wie können wir den historischen Wandel gesellschaftlicher Differenzierungsformen fassen - und welche Rolle spielt das Mittelalter dabei5? Er nimmt dazu die auch von Oexle geäußerte Kritik an älteren Theorieannahmen auf: Funktionale Differenzierung, so Pollack, entstand bereits im Mittelalter.

In seiner Auseinandersetzung schlägt er insgesamt vor, den historischen Verlauf gesellschaftlicher Differenzierung in der westlichen Moderne neu zu untersuchen. Er verfolgt - exemplarisch für weitere gesellschaftliche Differenzierungsprozesse - die Differenzierung der gesellschaftlichen Bereiche Religion und Politik und adaptiert dabei Annahmen verschiedener soziologischer Differenzierungstheorien, insbesondere derjenigen Luhmanns ${ }^{6}$. Er schlägt aber gleichzeitig vor, die systemtheoretische Herangehensweise zugunsten einer historisch präziseren, akteursorientierten Perspektive aufzugeben und nicht system-, sondern handlungstheoretisch vorzugehen - eine signifikante Abweichung von Ansätzen Luhmanns, die für die historische Präzisierung wichtige Potentiale eröffnet. Inhaltlich schlägt Pollack vor, den Beginn funktionaler Differenzierung zwischen Religion und Politik bereits im Hochmittelalter zu suchen und nicht, wie üblich, mit dem Beginn der Neuzeit anzusetzen. In einer mehrstufigen historischen Auseinandersetzung konstatiert er ein graduelles Auseinanderfallen von Funktionen und Codes von geistlicher und weltlicher Herrschaft, das von Konflikten zwischen weltlichen Herrschern und Papsttum im Mittelalter angetrieben wird. Diesen Prozess fasst er als „Emergenz“ einer funktionalen Differenzierung von Religion und Politik auf, der wesentlich von den religiösen Initiativen des Papsttums angetrieben werde ${ }^{7}$.

Pollacks Frage nach der historischen Operationalisierung von Differenzierungstheorie möchte ich im Folgenden aufgreifen und dabei seine Ansätze diskutieren und um forschungsgeschichtliche Überlegungen erweitern. Die Form des Kommentars scheint dabei in Teilen noch durch. Doch verfolgt der vorliegende Text

und Königtum im Mittelalter. Ein Kommentar zum Beitrag Detlef Pollacks, jeweils in diesem Band. Der Band zu einer vorausgehenden, thematisch stark verknüpften Münsteraner Tagung erschien als KARL GABRIEL - CHRISTEL GÄRTNER - DETLEF POLlACK (Hgg.), Umstrittene Säkularisierung. Soziologische und historische Analysen zur Differenzierung von Religion und Politik, Berlin 2012. Zu einer weiteren Tagung vgl. ANTJE FLÜCHTER, Tagungsbericht: The Making of Religion? ReDescribing Religious change in Pre-Modern Europe. 29. 4. 2011 - 30. 4. 2011, Harvard, in: H-Soz-uKult, 1. 8. 2011, http://hsozkult.geschichte.hu-berlin.de/tagungsberichte/id=3751 (letzter Zugriff 15. 9. 2012).

5 Zum Begriff der Differenzierung vgl. UwE SCHIMANK, Theorien gesellschaftlicher Differenzierung, Opladen 2000; DERS., Differenzierung und Integration der modernen Gesellschaft. Beiträge zur Akteurzentrierten Differenzierungstheorie 1, Wiesbaden 2005; HARTMANN TYRELL, Soziale und gesellschaftliche Differenzierung. Aufsätze zur soziologischen Theorie, Wiesbaden 2008.

${ }^{6}$ Vgl. zu Luhmann hier allgemein CLAUDIO BARALDI - GIANCARLO CORSI - ELENA EsPOSITO, GLU: Glossar zu Niklas Luhmanns Theorie Sozialer Systeme, Frankfurt a. M. 1997; GEORG KNEER ARMin NASSEHI, Niklas Luhmanns Theorie sozialer Systeme, München 31997; FrANK BECKER (Hg.), Geschichte und Systemtheorie. Exemplarische Fallstudien, Frankfurt a. M. 2004.

7 Vgl. so eine der eingangs geäußerten Hauptthesen bei, POLLACK, Die Genese (wie Anm. 4) Einleitungspassage. 
darüberhinausgehende Ziele. Er möchte zunächst unterstreichen, dass nur schwierig auf historische Differenzierungsformen zugegriffen werden kann, da das Erbe der älteren Forschung unseren Blick auf Differenzierung im Mittelalter noch stark prägt. Weiterhin scheint mir auch klärungsbedürftig, welche historischen Verlaufsannahmen mit einer Annahme fortschreitender Differenzierung verknüpft sind, und welche Art von Zäsuren sich für die Geschichte funktionaler Differenzierung postulieren lassen.

Diese Fragen scheinen auch über die hier vorliegende exemplarische Auseinandersetzung hinaus produktiv, führen sie doch zur Klärung grundlegender Verlaufsannahmen und Kategorien. Ein Ansatz bei der Differenzierungstheorie könnte tatsächlich eine wichtige Grundlage für weitere Dialoge zwischen Erforschern moderner und mittelalterlicher Religion bilden. Eine solche interdisziplinäre Annäherung scheint im Moment für verschiedene Beteiligte essentiell: In Soziologie, Religionswissenschaft und Politikwissenschaft wird intensiv um eine Dynamisierung der alten Großtheorien von Säkularisierung und Modernisierung gerungen. Umstritten ist besonders die Rolle der Religion ${ }^{8}$ : Zwar scheint der historische Bedeutungsverlust von Religion unübersehbar und nicht ohne weiteres reversibel, so dass mit einer unmittelbaren 'Rückkehr der Religion' nicht zu rechnen ist. Doch spielt Religion offenbar auch nicht die zunehmend marginale Rolle, die ältere Theorien ihr zuwiesen, sondern erweist sich bis heute als gesellschaftlich produktive Kraft. Daher werden die historischen Verknüpfungen und die Verlaufsmodelle von Modernisierung, Säkularisierung und gesellschaftlicher Differenzierung hinterfragt ${ }^{9}$. Eine historisch fundierte Revision älterer Einschätzungen wird man aber nur erreichen können, wenn man auch einen neuen Blick auf die langfristigen historischen Verläufe entwickelt, und

\footnotetext{
8 Vgl. zu dieser Debatte UlRiCH Willems u. a. (Hgg.), Moderne und Religion. Kontroversen um Modernität und Säkularisierung, Bielefeld 2013; GABRIEL - GÄRTNER - POLLACK (Hgg.), Umstrittene Säkularisierung (wie Anm. 4); DETLEF POLLACK, Rückkehr des Religiösen? Studien zum religiösen Wandel in Deutschland und Europa II, Tübingen 2009; JosÉ CASANOVA, Europas Angst vor der Religion, Berlin 2009, und bereits DERS., Public Religions in the Modern World, Chicago 1994; FrIEDRICH WILHELM GRAF, Die Wiederkehr der Götter: Religion in der modernen Kultur, München 2007; PIPPA NORRIS - RONALD INGLEHART, Sacred and Secular. Religion and Politics Worldwide, Cambridge (MA) 2004; PETER L. BERGER, The Desecularization of the World: Resurgent Religion and World Politics, Washington (DC) 1999.

${ }_{9} \mathrm{Vgl}$. (zumeist exemplarisch für die Arbeit jüngerer Forschungsverbünde) HANS G. KIPPENBERG JÖRG RÜPKE - KOCKU VON STUCKRAD (Hgg.), Europäische Religionsgeschichte. Ein mehrfacher Pluralismus, 2 Bde., Göttingen 2009; VOLKHARD KRECH - MARION STEINICKE (Hgg.), Dynamics in the History of Religions between Asia and Europe. Encounters, Notions and Comparative Perspectives (Dynamics in the History of Religions 1) Leiden - Boston 2012; CHAD MEISTER (Hg.), The Oxford Handbook of Religious Diversity, Oxford 2010; JAMAL MALIK - JÜRGEN MANEMANN (Hgg.), Religionsproduktivität in Europa: Markierungen im religiösen Feld, Münster 2009. Zur Kritik an der Erklärungskraft der älteren Makrotheorien und Großerzählungen vgl. besonders (jeweils mit weiteren Verweisen) HANS JOAS, Gefährliche Prozessbegriffe. Eine Warnung vor der Rede von Differenzierung, Rationalisierung und Modernisierung, in: GABRIEL - GÄRTNER - POLLACK (Hgg.), Umstrittene Säkularisierung (wie Anm. 4) S. 603-622; AlBRECHT KOSCHORKE, 'Säkularisierung' und 'Wiederkehr der Religion'. Zu zwei Narrativen der europäischen Moderne, in: WiLLEMS u. a. (Hgg.), Moderne und Religion (wie Anm. 7) S. 237-260.
} 
Detlef Pollacks Interesse an einer Neueinschätzung des Mittelalters dürfte hier seine Wurzeln haben. Seine Initiative illustriert ein neues Interesse der Gegenwartsforschung an dieser Epoche, die ja sozusagen als die Zeit der Religiosität schlechthin gilt.

Dass die Mittelalterforschung nur gewinnen kann, wenn sie an der interdisziplinären Debatte teilnimmt und so die eigene Relevanz deutlicher herausstellt, muss kaum betont werden. Die von Pollack aufgerufenen Themenfelder kommen ihren Interessen stark entgegen: Die Frage nach historischen Formen religiöser Diversität ist in den letzten Jahren intensiv aufgenommen worden, in der deutschsprachigen Forschung vor allem in Arbeiten zu inter- und transkulturellen Kontakten und religiösen Kontaktzonen ${ }^{10}$. Zudem laufen Debatten an, in denen die internationale Mediävistik sich an eine längst überfällige Rezeption jüngerer religionswissenschaftlicher und religionssoziologischer Theoriebildung macht, zum Beispiel in Auseinandersetzungen mit dem Begriff der Religion, des Religiösen, des Sakralen und deren verschiedenen Dynamiken ${ }^{11}$. Da diese Themen sich

${ }^{10}$ Vgl. exemplarisch an rezenten Sammelbänden aus dem deutschsprachigen Bereich MARK VON DER HÖH - NiKOlAS JASPERT - JENNY RAHEL OESTERLE (Hgg.), Cultural Brokers between Religions. Border-Crossers and Experts at Mediterranean Courts, München 2013; RANIA ABDELLATIF u. a. (Hgg.), Acteurs des transferts culturels en Méditerranée médiévale (Ateliers des DHI Paris 9) München 2012; Rania AbDellatif u. a. (Hgg.), Construire la Méditerranée, penser des transferts culturels. Approches historiographiques et perspectives de recherche (Ateliers des Deutschen Historischen Instituts Paris 8) München 2012; Michael Borgolte - MATTHias M. TischleR (Hgg.), Transkulturelle Verflechtungen im mittelalterlichen Jahrtausend. Europa, Ostasien, Afrika, Darmstadt 2012; Michael Borgolte u. a. (Hgg.), Integration und Desintegration der Kulturen im europäischen Mittelalter, Berlin 2011; DERS. - BERND SCHNEIDMÜLLER (Hgg.), Hybride Kulturen im mittelalterlichen Europa. Vorträge und Workshops einer internationalen Frühlingsschule - Hybrid Cultures in Medieval Europe. Papers and Workshops of an International Spring School (Europa im Mittelalter. Abhandlungen und Beiträge zur historischen Komparatistik 16) Berlin 2010; KLAUS HERBERS - NikOLAS JASPERT (Hgg.), Integration - Segregation - Vertreibung. Religiöse Minderheiten und Randgruppen auf der Iberischen Halbinsel (7.-17. Jahrhundert) (Geschichte und Kultur der Iberischen Welt 8) Münster 2011; ANDREAS SPEER - LYDIA WEGENER (Hgg.), Wissen über Grenzen. Arabisches Wissen und lateinisches Mittelalter (Miscellanea Mediaevalia 33) Berlin New York 2006; Almut HÖFERT - ARmando SAlvatore (Hgg.), Between Europe and Islam: Shaping Modernity in a Transcultural Space, Frankfurt - New York 2000, sowie die Übersicht bei DANIEL KÖNIG, Arabic-Islamic Perceptions of Europe in the Middle Ages, in: DAVID THOMAS Alex Mallet (Hgg.), Christian-Muslim Relations. A Bibliographical History, 5, Leiden 2013, S. 1734.

11 Den Anstoß bildeten interkulturell vergleichende Fragen, etwa von TALAL ASAD, Genealogies of Religion. Discipline and Reasons of Power in Christianity and Islam, Baltimore - London 1993; und DERS., Formations of the Secular: Christianity, Islam, Modernity, Stanford 2003. Mediävistische Überlegungen insbesondere bei CHRISTINE CALDWELL AMES, Medieval Religious, Religions, Religion, in: History Compass 10, 2012, S. 334-352; DIES., Does Inquisition belong to Religious History?, in: The American Historical Review 110/1, 2005, S. 11-37; DAVID L. D’AvrAY, Medieval Religious Rationalities. A Weberian Analysis, Cambridge (MA) 2010, sowie bereits JOHN VAN ENGEN, The Christian Middle Ages as a Historiographical Problem, in: DeRs., Religion in the History of the Medieval West (Variorum Collected Studies Series 793) Aldershot 2004, I: S. 519-552 (ursprünglich 1986). Zu Konzepten des Sakralen vgl. BERNDT HAMM - KLAus Herbers - HeIDRUN STEINKECKS (Hgg.), Sakralität zwischen Antike und Neuzeit (Beiträge zur Hagiographie 6) Stuttgart 2007; 
differenzierungstheoretisch genauer fassen lassen - ja, die Begriffe sogar eigentlich erst bei Betrachtung der Differenzierung von Religion genaue Konturen gewinnen bildet die Differenzierungstheorie ein ideales Feld interdisziplinärer Vermittlung.

Doch sowohl Soziologie wie Geschichtswissenschaft müssten sich dazu meiner Ansicht nach zunächst einmal Rechenschaft über ihr jeweiliges differenzierungstheoretisches Erbe ablegen. Ich möchte im Folgenden nicht nur eine von Detlef Pollacks Ansatz abweichende differenzierungstheoretische Perspektive verfolgen. Ich möchte auch darauf hinweisen, dass ein Haupthindernis für die Diskussion theoretischer Aspekte - wie häufig in interdisziplinären Debatten - in dem ganz unterschiedlichen Forschungsstand besteht, der bei den Beteiligten herrscht. Ganz wie Oexle gegenüber Luhmann bin ich der Meinung, dass Pollacks Mittelalterbild die Vielfalt mittelalterlicher Phänomene wiederum zu reduzieren droht $^{12}$. Grob zugespitzt, kann man sein Mittelalter, dem er ausdrücklich die „Genese der westlichen Moderne“ zuweist, als Mittelalterbild eines modernisierungstheoretischen 'Rise of the West' identifizieren ${ }^{13}$. Es ist selbst stark von älteren modernisierungstheoretischen Modellen inspiriert, die neue Anregungen Pollacks sozusagen durch eine überholte inhaltliche Füllung konterkarieren. Die aktualisierten differenzierungstheoretischen Ansätze werden also mit historischen Befunden unterlegt, die selbst älteren differenzierungstheoretischen Annahmen verpflichtet sind. Das bewirkt eine Feedbackschleife in der interdisziplinären Diskussion, die bei mehreren Autoren sichtbar wird ${ }^{14}$. Nicht zuletzt steht auch in der internationalen Mediävistik eine Reflexion des modernisierungstheoretischen Erbes in Teilen aus.

BERNDT HAMM, Heiligkeit im Mittelalter. Theoretische Annäherungen an ein interdisziplinäres Forschungsvorhaben, in: NINE MIEDEMA - Rudolf SunTRUP (Hgg.), Literatur - Geschichte Literaturgeschichte. Beiträge zur mediävistischen Literaturwissenschaft. Festschrift für Volker Honemann zum 60. Geburtstag, Frankfurt a. M. 2003, S. 627-645. Zu Wahrnehmungen religiöser Identitäten und Zuschreibungen vgl. HANS MARTIN KRÄMER - JENNY RAHEL OESTERLE - ULRIKE VORDERMARK (Hgg.), Labeling the Religious Self and Others: Reciprocal Perceptions of Christians, Muslims, Hindus, Buddhists, and Confucians in Medieval and Early Modern Times (Comparativ 24) Leipzig 2010; ANNA AURAST - HANS-Werner GOETZ (Hgg.), Die Wahrnehmung anderer Religionen im früheren Mittelalter. Terminologische Probleme und methodische Ansätze (Hamburger Geisteswissenschaftliche Studien zu Religion und Gesellschaft 1) Münster - Berlin 2012, sowie jüngst KNUT MARTIN STÜNKEL, Una sit religio: Religionsbegriffe und Begriffstopologien bei Cusanus, Llull und Maimonides, Würzburg 2013.

12 Ich habe dieses Argument bereits im Rahmen der erwähnten Münsteraner Tagung 2011 vorgetragen (SITA STECKEL, Säkularisierung, Desakralisierung und Resakralisierung: Transformation hoch- und spätmittelalterlichen gelehrten Wissens als Ausdifferenzierung von Religion und Politik, in: GABRIEL GÄRTNER - POLLACK [Hgg.], Umstrittene Säkularisierung [wie Anm. 4] S. 134-175). Es fußt wesentlich auf den Überlegungen Oexles, vgl. die Literatur oben bei Anm. 3.

13 Vgl. zu Konzepten des Westens hier nur Alastair BOnNETT, The Idea of the West, Basingstoke 2004.

14 Vgl. z. B. auch HARTMAN TYRELl, Investiturstreit und gesellschaftliche Differenzierung Überlegungen aus soziologischer Sicht, in: GABRIEL - GÄRTNER - POLLACK (Hgg.), Umstrittene Säkularisierung (wie Anm. 4) S. 39-77. 
Ich möchte daher im Folgenden die Frage nach funktionaler Differenzierung im Mittelalter forschungsgeschichtlich einrahmen und skizzenhaft mehrere Problemzusammenhänge aufweisen (ohne dabei allerdings mehr als versuchsweise, gerade bibliographisch unvollständige Sondierungen bieten zu können). Zunächst möchte ich die Anfänge historischer Verlaufsannahmen über gesellschaftliche Differenzierung in der Mittelalterforschung skizzieren und die Entstehung eines Mittelalterbildes des 'Rise of the West' umreißen, dem diverse weitere soziologische, rechtswissenschaftliche und historische Forschungen verpflichtet bleiben (Abschnitt 2). Dann möchte ich auf der Basis jüngerer geschichtswissenschaftlicher Arbeiten Alternativen zu Pollacks historischem Verlaufsmodell formulieren (Abschnitt 3). Schließlich möchte ich - im Sinne einer Vorarbeit für weitere Forschungen - die differenzierungstheoretischen Verlaufsannahmen der Feldtheorie Pierre Bourdieus und der Systemtheorie Niklas Luhmanns diskutieren und auf Nutzen für historische Fragestellungen abklopfen. (Abschnitt 4).

Die Position, die dabei entwickelt wird, lässt sich im Vorhinein an zwei Hauptanliegen umreißen. Erstens ist es mir ein ausdrückliches Ziel, der schon bei Luhmann vorschnell reduzierten Vielfalt des Mittelalters Raum zu schaffen. Wenn man einen dynamischen Rahmen regional und chronologisch veränderlicher gesellschaftlicher Differenzierung ansetzt, scheint Europa im Mittelalter nicht von einer 'Entstehung' funktionaler Differenzierung geprägt, sondern von wiederholten Dynamiken der 'Neu-Differenzierung'. Die Trennung von Religion und Politik, die Pollack fokussiert, erscheint mir entsprechend weniger interessant als historische Varianten ihrer Verknüpfung.

Ich schließe daher an verschiedene Ansätze aus der Soziologie, Neuzeitgeschichte und Religionswissenschaft an, die in letzter Zeit zur Überprüfung älterer linearer Verlaufsmodelle aufgerufen und deren einseitig identitätsstiftende narrative Konstruktion kritisiert haben. Mit ihnen möchte ich davon ausgehen, dass sich die alten Modernisierungserzählungen dynamisieren lassen: Während eine Fortschrittsgeschichte für den Bereich der Medizin- oder Technikgeschichte Sinn ergeben mag, kann man an den Schnittstellen zwischen Religion und anderen gesellschaftlichen Bereichen im Mittelalter wie in der Neuzeit wiederholte Konjunkturen feststellen. Sie lassen sich nach jüngeren Vorschlägen als Sakralisierungen und Entsakralisierungen, als ,Wanderungen des Religiösen“ (Alexandra Walsham) oder als „Grenzarbeiten am religiösen Feld“ (Astrid Reuter) fassen ${ }^{15}$.

15 Vgl. stellvertretend für viele jüngere soziologische Ansätze zu Sakralisierung und Entsakralisierung Nicholas Jay Demerath (III), Secularization and Sacralization Deconstructed and Reconstructed, in: JAMES A. BECKFORD - NiChOlas JAY DEMERATH (III) (Hgg.), The SAGE Handbook of the Sociology of Religion, London 2007, S. 57-80. Aus historischer Sicht AlEXANDRA WALSHAM, The Reformation and the Disenchantment of the World Reassessed, in: The Historical Journal 51/2, 2008, S. 497-528, besonders S. 517-528; ausführlichere Überlegungen zum Begriff der „Migrations of the Holy“ (ebd. S. 517), der auf John Bossy zurückgeht, demnächst in ALEXANDRA WALSHAM, Migrations of the Holy. Explaining Religious Change in Medieval and Early Modern Europe, in: 
Zweitens scheint es mir ein Anliegen für die interdisziplinäre Forschung zu sein, für die Erforschung solcher Prozesse einen übergreifenden, ergebnisoffenen und globalgeschichtlich erweiterbaren theoretischen und methodischen Rahmen zu entwickeln. Denn es scheint ausdrücklich noch eine offene Forschungsfrage zu sein, wie es zur Entstehung multipler westlicher und nichtwestlicher Modernen kam und welche differenzierungstheoretischen Formationen diesen Modernen vorausgingen und sie bedingten. Da globale kulturelle Dynamiken und Asymmetrien im Moment neu erforscht werden, etwa für Europa und Asien, sind hier neue Ergebnisse zu erwarten ${ }^{16}$. Das weite und fruchtbare Forschungsfeld sollte nicht vorschnell verengt werden, indem man Differenzierungstheorie einseitig auf die Erforschung einer westlichen Moderne bezieht ${ }^{17}$. Eine historische Operationalisierung von Differenzierungstheorien scheint im Gegenteil gerade daher wünschenswert, da sie geeignete Ansatzpunkte für die weitere vergleichende Erforschung verschiedener Kulturen liefert.

\section{MODERNEN UND IHR MITTELALTER: VON BURCKHARDT ÜBER WEBER ZUM 'RISE OF THE WEST'}

Doch vor dem Blick in die Zukunft mag ein Blick in die Vergangenheit klärend sein. Um einleitend die enge Verflechtung historischer und soziologischer Annahmen

Journal of Medieval and Early Modern Studies 44 (in Druckvorbereitung - ich danke Alexandra Walsham sehr herzlich für die Überlassung des Aufsatzmanuskripts, das auf der in Anm. 4 erwähnten Tagung an der Harvard University vorgetragen wurde). Zum Begriff der Grenzarbeiten am religiösen Feld vgl. ASTRID REUTER, Charting the Boundaries of the Religious Field. Legal Conflicts over Religion as Struggles over Blurring Borders, in: Journal of Religion in Europe 2, 2009, S. 1-20; DIES., Grenzarbeiten am religiösen Feld. Religionsrechtskonflikte und -kontroversen im Verfassungsstaat, in: MALIK - MANEMANN (Hgg.), Religionsproduktivität in Europa (wie Anm. 8) S. 101-115.

16 Vgl. verschiedene Querschnitte in JÜrgen OsterhammeL (Hg.), Weltgeschichte (Basistexte Geschichte 4) Stuttgart 2008; an aktuellen Arbeiten vgl. etwa Überlegungen im Rahmen des Exzellenzclusters „Asia and Europe in a Global Context“ in Heidelberg, z. B. ANTJE FLÜCHTER SUSAN Richter (Hgg.), Structures on the Move: Technologies of governance in transcultural encounter, Heidelberg 2012, oder des University Research Priority Program (URPP) „Asia and Europe“ in Zürich, z. B. SHALINI RANDERIA - ANDREAS ECKERT (Hgg.), Vom Imperialismus zum Empire - Nicht-westliche Perspektiven auf Globalisierung, Frankfurt a. M. 2009.

${ }_{17}$ Pollack verknüpft seine historische Herleitung einer Trennung von Religion und Politik mit der Frage, inwiefern sie eine „endogene“ Entwicklung der westlichen Gesellschaften sei. Dabei positioniert er sich gegen jüngere Überlegungen zu multiple modernities und Verflechtungsgeschichte, ohne diese voraussetzungsreichen globalgeschichtlichen Überlegungen auf engem Raum genauer ausführen zu können (vgl. POLLACK, Die Genese [wie Anm. 4] bei Anm. 2, mit Bezug auf SHALINI RanderiA, Geteilte Geschichte und verwobene Moderne, in: JÖRN RÜSEN [Hg.], Zukunftsentwürfe. Ideen für eine Kultur der Veränderung. Frankfurt a. M. - New York 1999, S. 87-96; SHMUEL N. EISENSTADT, Multiple modernities. Analyserahmen und Problemstellung, in: THORSTEN BONACKER - ANDrEAS RECKWITZ [Hgg.], Kulturen der Moderne. Soziologische Perspektiven der Gegenwart, Frankfurt a. M. - New York 2007, S. 19-45.) Auch ich kann auf dieses voraussetzungsvolle Thema nur am Rande eingehen, möchte aber stärker als Pollack die Notwendigkeit weiterer Forschungen unterstreichen, da mir gerade die Religionsgeschichte in der vorliegenden Forschung unterbetont scheint. 
zur gesellschaftlichen Differenzierung vor Augen zu führen, kann man sich zunächst Oexles Feststellung in Erinnerung rufen, dass Aussagen über das Mittelalter „zumeist vielmehr Aussagen über die Moderne“ sind und waren ${ }^{18}$. Tatsächlich haben die verschiedenen Modernen des 19. und 20. Jahrhunderts jeweils Mittelalterbilder geprägt, die differenzierungstheoretische Komponenten aufweisen. Dieses Erbe kann hier zunächst skizzenhaft vorgestellt werden.

Als wesentliche Verschiebung von Konzepten gesellschaftlicher Differenzierung kann man mit Oexle die Abkehr von älteren Vorstellungen einer mittelalterlichen „Einheitskultur“" nennen ${ }^{19}$. Diese Vorstellung war in den beiden großen Erzählungen des 19. Jahrhunderts vom Mittelalter dominant gewesen, dem 'aufgeklärten' und dem 'romantischen' Mittelalterbild ${ }^{20}$. Für ersteres kann Jacob Burckhardts berühmtes Werk der „Cultur der Renaissance in Italien“ von 1860 stehen, das den Menschen des Mittelalters in einer religiösen Einheitswelt gefangen sah, aus der ihn erst die Individualisierung der Neuzeit befreite. 'Romantische' Mittelalterbilder wandten diese Idee ins Positive und schwärmten beispielsweise von einer harmonischen, geordneten Gesellschaft, die dem Einzelnen Geborgenheit bot, bis sie in den Kämpfen der Moderne zerbrach und zerfiel.

Die Idee einer mittelalterlichen Einheitswelt wurde schon von frühen soziologischen Theoriebildungen aufgenommen, die im gesellschaftlichen Umbruch des 19. Jahrhunderts fragen mussten, was die Gesellschaft ihrer Gegenwart eigentlich noch zusammenhielt. Die Idee eines gesellschaftlichen 'Zerfalls' wurde in verschiedenen Disziplinen und Milieus dann unterschiedlich akzentuiert: In der Mittelaltergeschichte wurde im Zusammenhang mit diesen Themen vor allem das Verhältnis von Kirche und Staat diskutiert, das im „,zweiten konfessionellen Zeitalter“ des 19. Jahrhunderts für die aufstrebenden Nationalstaaten in neuer Weise akut wurde ${ }^{21}$. Besonders über den Kulturkampf verknüpften sich dabei Konzepte der Säkularisierung 22 mit historischen Forschungen, etwa $\mathrm{zu}$ den hochmittelalterlichen Auseinandersetzungen zwischen Papst und Kaiser ${ }^{23}$. In der deutschen Mediävistik

18 Vgl. OexLE, Das entzweite Mittelalter (wie Anm. 3) S. 12.

${ }^{19}$ Vgl. OTto Gerhard OeXle, Das Mittelalter - Bilder gedeuteter Geschichte, in: JÁNOS M. BAK u. a. (Hgg.), Gebrauch und Missbrauch des Mittelalters, 19.-21. Jahrhundert (Mittelalter-Studien 17) München 2009, S. 21-42, besonders S. 33-37.

${ }^{20}$ Vgl. besonders OexLE, Das entzweite Mittelalter (wie Anm. 3) passim.

${ }^{21} \mathrm{Vgl}$. Olaf BlaschKe (Hg.), Konfessionen im Konflikt. Deutschland zwischen 1800 und 1970 - ein zweites konfessionelles Zeitalter, Göttingen 2002.

22 Vgl. zu Konzept und Begriff der Säkularisierung allgemein HERMANN LÜBBE, Säkularisierung. Geschichte eines ideenpolitischen Begriffs, Freiburg 32003; HERMANN ZABEL, Verweltlichung / Säkularisierung. Zur Geschichte einer Interpretationskategorie, Münster 1968; ULRICH RUH, Säkularisierung als Interpretationskategorie. Zur Bedeutung des christlichen Erbes in der modernen Geistesgeschichte, Freiburg 1981.

23 Vgl. MANuEL BORUTTA, Genealogie der Säkularisierungstheorie. Zur Historisierung einer großen Erzählung der Moderne, in: Geschichte und Gesellschaft 36/3, 2010, S. 347-376; zum historischen Umgang mit Canossa vgl. BERND SCHNEIDMÜller, Canossa und der harte Tod der Helden, in: JÖRG JARNUT - MATTHIAS WEMHOFF (Hgg.), Vom Umbruch zur Erneuerung? Das 11. und beginnende 12. 
konnte man mittelalterlichen deutschen Herrschern beispielsweise gut einen geschichtlichen Fortschritt durch die Abwendung vom Papsttum im Investiturstreit und eine damit einhergehende Erschütterung der mittelalterlichen Einheitswelt zuschreiben. Vorstellungen einer 'Entwicklung' von einer mittelalterlichen Einheitswelt zum modernen, von der Kirche getrennten Staat des 19. Jahrhunderts dürften sich zudem harmonisch in das stark von Hegel beeinflusste Geschichtsbild der deutschen Historiker gefügt haben. Schon Hegel hatte ja einen positiven Begriff der 'Entwicklung' eingebracht ${ }^{24}$. Doch auch theologisch-religiöse Grundhaltungen wirkten sich aus. Für den protestantischen Theologen Ernst Troeltsch erschien um 1912 das Mittelalter noch als „Einheitswelt“25. Er bezog diese Vorstellung aber nicht auf Mentalitäten wie Burckhardt, sondern leitete sie aus dem mittelalterlichen „Thomismus“ her, also der institutionalisierten Papstkirche mit ihrem Kontrollanspruch über Wissenschaft und Politik. Damit positionierte er sich gleichzeitig gegen den zwischenzeitlich erstarkten katholischen Neothomismus des 19. Jahrhunderts ${ }^{26}$.

Eine Abkehr vom Bild der mittelalterlichen Einheitswelt zugunsten einer deutlich dynamischeren und nuancierteren Sichtweise findet sich dann bei Max Weber ${ }^{27}$. Sein Konzept gesellschaftlicher „Wertsphären“ nahm das ursprünglich negative Element des Zerfalls nun in positiver Weise als gesellschaftliche Ausdifferenzierung und Prozess der Rationalisierung auf. Weber nahm einen historisch kontingenten und multilinearen Prozess der Freisetzung unterschiedlicher Wertsphären an, innerhalb dessen sich eigene Logiken und Rationalitäten der Sphären

Jahrhundert. Positionen der Forschung (Mittelalter Studien 13) München 2006, S. 103-131, besonders S. 103-108; MATTHIAS PAPE, „Canossa“ - eine Obsession? Mythos und Realität, in: Zeitschrift für Geschichtswissenschaft 54, 2006, S. 550-572. Als Vorlauf wäre möglicherweise auch die Sybel-FickerKontroverse einzubeziehen, vgl. THOMAS BRECHENMACHER, Wieviel Gegenwart verträgt historisches Urteilen? Die Kontroverse zwischen Heinrich von Sybel und Julius Ficker über die Bewertung der Kaiserpolitik des Mittelalters (1859-1862), in: ULRICH MUHLACK (Hg.), Historisierung und gesellschaftlicher Wandel in Deutschland im 19. Jahrhundert, Berlin 2003, S. 87-112.

24 Der äußerst voraussetzungsreiche Begriff der „Entwicklung“ wurde insbesondere in Hegels Vorstellung historischer Dialektik genutzt, wo er ein „Auseinanderlegen“ und damit eine Differenzierung von innen heraus beinhaltete, vgl. hier nur KLAUS WEYAND, Art. 'Entwicklung 2', in: Historisches Wörterbuch der Philosophie 2, 1972, Sp. 550-557.

25 Vgl. ERnst Troeltsch, Gesammelte Schriften, 1: Die Soziallehre der christlichen Kirchen, besonders Kapitel II, S. 178-426, zum Begriff „Einheitskultur“, S. 178-185.

26 Vgl. hier nur die Literaturhinweise bei OTTO HERMANN PESCH, Art. 'Thomas von Aquin/Thomismus/Neuthomismus', besonders 6: 'Der Thomismus/Neuthomismus', in: TRE 33, 2002, S. 433-474.

27 Vgl. zum Mittelalterhistoriker Max Weber OTto GerhaRd OeXle, Priester - Krieger - Bürger. Formen der Herrschaft in Max Webers 'Mittelalter', in: EDITH HANKE - WOLFGANG J. MOMMSEN (Hgg.), Max Webers Herrschaftssoziologie. Studien zu Entstehung und Wirkung, Tübingen 2001, S. 203-222. Zur historischen Operationalisierung aktuell auch DAVID L. D'AVRAY, Rationalities in History. A Weberian Essay in Comparison, Cambridge (MA) 2010, und DERS., Medieval religious rationalities (wie Anm. 11); mit Warnung in Bezug auf die Kategorien der Rationalisierung JOAS, Gefährliche Prozessbegriffe (wie Anm. 9). 
entfalten konnten ${ }^{28}$. Religiöse Impulse sah er oft als wesentliches Movens dafür an, doch tritt die Eigenlogik der Wertsphären (bei ihm ökonomische, politische, ästhetische, erotische und intellektuelle Sphären u. a.) erst mit dem Verblassen der Religion voll heraus ${ }^{29}$. Wiewohl Weber dies nicht als Zerfall sah, kann man seine Arbeiten noch mit den älteren Vorläufern $\mathrm{zu}$ einem „Zerfalls“- oder „Dekompositionsparadigma“ in der Sicht auf gesellschaftliche Differenzierung zusammenfassen ${ }^{30}$.

Wiewohl Weber den Aufstieg einer spezifisch europäischen Rationalität zur Weltgeltung ausdrücklich als kontingent ansah, prägten seine Ansätze doch ein historisches Deutungsmuster. Die Ausdifferenzierung in verschiedene, zunehmend autonomen Regeln folgende Bereiche erschien als Entwicklungslogik moderner Gesellschaft. Diese Idee wurde früh in der Mittelaltergeschichte rezipiert und hat dort prägende Spuren hinterlassen: Nach der Verselbstständigung und Ausdifferenzierung bestimmter gesellschaftlicher Sphären wie Recht, Politik und Religion zu fragen, ist bis heute eine beliebte theoretische Rahmung.

Schon in der ersten Hälfte des 20. Jahrhunderts schlug sich diese Tendenz zum Beispiel in weiteren Forschungen zu den Auseinandersetzungen zwischen geistlicher und weltlicher Gewalt nieder. Nachdem eine Reihe katholischer Gelehrter eine Verrechtlichung der päpstlichen Herrschaft seit dem Hochmittelalter beschrieben hatte ${ }^{31}$, legten Mittelalterhistoriker wie Walter Ullmann († 1983) und Gerd Tellenbach († 1999) Darstellungen zur Auseinanderentwicklung von geistlicher und weltlicher Herrschaft vor, die sie auch mit einer Trennung von Recht, weltlicher Politik und religiöser Autorität verknüpften. Insbesondere Ullmans „The Growth of Papal Government" machte die Verselbständigung der weltlichen Politik und des Rechts stark und wurde, vom Emigranten Ullmann auf Englisch verfasst, international rezipiert $^{32}$. Andere Forschungen fragten nach der Freisetzung von Wissenschaft, insbesondere der Amerikaner Charles Homer Haskins († 1937) mit seiner Idee einer

28 Vgl. vor allem die ,Zwischenbetrachtung“, in: MAX WEBER, Gesammelte Aufsätze zur Religionssoziologie, 1, Tübingen ${ }^{5} 1963$, S. 536-573.

${ }^{29}$ Das klassische Beispiel bleibt die Darstellung der Wirtschaftsethik des Protestantismus: MAX WEBER, Gesammelte Aufsätze (wie Anm. 33) S. 17-206.

${ }^{30} \mathrm{Vgl}$. zur Gegenüberstellung von Dekompositions- und späterem Emergenzparadigma knapp GEORG KNEER, Differenzierung bei Luhmann und Bourdieu. Ein Theorienvergleich, in: ARMIN NASSEHI Gerd NollmanN (Hgg.), Bourdieu und Luhmann. Ein Theorienvergleich, Frankfurt a. M. 2004, S. $25-57$.

31 Vgl. besonders AUguSTIN FLICHE, La reforme grégorienne, 3. Bde., Louvain u. a. 1924-1937; PAUL FOURNIER - GABRIEL LE BRAS, Histoire des collections canoniques en Occident depuis les fausses décrétales jusqu'au décret de Gratien, 2 Bde., Paris 1931-1932, ND Aalen 1972.

32 Vgl. Walter Ullmann, The Growth of Papal Government in the Middle Ages. A Study in the Ideological Relation of Clerical to Lay Power, London 1955. Deutsch: Die Machtstellung des Papsttums im Mittelalter. Idee und Geschichte, Graz u. a. 21969; GERD TELLENBACH, Libertas. Kirche und Weltordnung im Zeitalter des Investiturstreites (Forschungen zur Kirchen- und Geistesgeschichte 7) Stuttgart 1936, ND Stuttgart 1996, englisch bereits 1940 als DERS., Church, State, and Christian Society at the Time of the Investiture Contest, translated by RALPH FRANCIS BENNETT, Oxford 1940 
„Renaissance of the Twelfth Century “33. Obwohl die Rezeption der paganen antiken Wissenschaft und der arabischen Aristoteleskommentare seit dem Hochmittelalter heute genaugenommen als religiöse Pluralisierung erscheint, wurde sie von Haskins als säkularisierende Freisetzung der Wissenschaft aus einer religiösen Fesselung dargestellt, also noch sehr stark im Sinne der Burckhardtschen Renaissance ${ }^{34}$.

Hier und da gab es auch Forschungen, die historische Intensivierungen von Religiosität untersuchten. Carl Erdmanns († 1945) „Entstehung des Kreuzzugsgedankens“ wäre als außergewöhnliches Beispiel einer Studie zu nennen, die nicht die Entkopplung von Religion und Politik, sondern deren kurzfristige Verflechtung und Instrumentalisierung thematisierte ${ }^{35}$. Ansonsten überließ man - mit wenigen Ausnahmen ${ }^{36}$ - das Religiöse zumeist der Theologie und den konfessionellen Kirchengeschichten.

Ein neues Mittelalterbild innerhalb der Mediävistik, das man den von Oexle diskutierten Varianten hinzufügen könnte, verdichtete sich dann mit der Rezeption der amerikanischen Modernisierungstheoretiker der Nachkriegszeit. Die heute als klassisch angesehene Modernisierungstheorie der 1950er und 1960er Jahre nutzte Webersche Konzepte der Ausdifferenzierung gesellschaftlicher Sphären in den strukturfunktionalistischen Überarbeitungen Talcott Parsons' ${ }^{37}$. Während Weber und diverse Historiker ihre Zugriffe kurz- und mittelfristig aufgebaut hatten und multilineare Entwicklungen verfolgten, brachte die amerikanische Modernisierungstheorie unilineare, langfristige und ausdrücklich teleologische

33 Vgl. Charles Homer Haskins, The Renaissance of the Twelfth Century, Cambridge (MA) 1927, sowie bereits DERS., The Rise of Universities, Ithaca (NY) - London 1957 (ursprünglich 1923); DERS., Studies in the History of Mediaeval Science, Cambridge (MA) 1924, ND New York 1960. Zu Konzepten mittelalterlicher Renaissancen vgl. auch GÉRARD PARÉ - ADRIEN MARIE BRUNET Pierre Tremblay, La Renaissance du XII e siècle. Les écoles et l'enseignement, Paris - Ottawa 1933; ERNA PATZELT, Die karolingische Renaissance. Beiträge zur Geschichte der Kultur des frühen Mittelalters, Wien 1924.

34 Vgl. zur Einordnung MARCIA COLISH, Haskins's Renaissance Seventy Years Later. Beyond AntiBurckhardtianism, in: The Haskins Society Journal 11, 1998 (erschienen 2003), S. 1-15; LEIDULF MELVE, 'The revolt of the medievalists'. Directions in Recent Research on the Twelfth-Century Renaissance, in: Journal of Medieval History 32, 2006, S. 231-256. Leider noch nicht zugänglich war mir FRANK REXROTH, Die scholastische Wissenschaft in den Meistererzählungen der europäischen Geschichte, in: KLAUS RIDDER - STEFFEN PATZOLD (Hgg.), Die Aktualität der Vormoderne (Europa im Mittelalter 23) Berlin 2013, S. 111-134.

35 Vgl. CARL ERDmann, Die Entstehung des Kreuzzugsgedankens (Forschungen zur Kirchen- und Geistesgeschichte 6) Stuttgart 1935, ND Darmstadt 1980.

${ }^{36}$ Als wichtige Ausnahmen, die diverse Forschungsfelder beeinflussten und prägten, wären allerdings die Arbeiten Herbert Grundmanns zu nennen. Besonders in HERBERT GRUNDMANN, Religiöse Bewegungen im Mittelalter. Untersuchungen über die geschichtlichen Zusammenhänge zwischen der Ketzerei, den Bettelorden und der religiösen Frauenbewegung im 12. und 13. Jahrhundert und über die geschichtlichen Grundlagen der deutschen Mystik (Historische Studien 276) Berlin 1935, verfolgte er ebenfalls eine Art Webersche Freisetzungslogik, indem er die Freisetzung der Religion von den Kirchen ins Auge fasste.

${ }^{37}$ Vgl. mit Verweisen WOLFGANG KNÖBL, Spielräume der Modernisierung, Weilerswist 2001, S. 155221; SCHIMANK, Theorien gesellschaftlicher Differenzierung (wie Anm. 5) S. 73-123. 
Perspektiven in die Theorie zurück - jedoch nicht aus theoretischen, sondern vielmehr aus praktischen, anwendungsorientierten Gründen. Wie zuletzt Wolfgang Knöbl nachgezeichnet hat, bildeten die aktive weltpolitische Rolle der USA und die Neugestaltung der ehemaligen Kolonialreiche einen spezifischen praktisch-politischen Kontext für sozialwissenschaftliche Theoriebildung ${ }^{38}$. Die Grenze zwischen modernen und 'noch nicht modernen' Staaten konkretisierte sich in einer 'Entwicklungspolitik' gegenüber den Ländern, die man nach dem Vorbild des Westens zu modernen Gesellschaften mit ausdifferenzierten politischen, ökonomischen und wissenschaftlichen Grundlagen umbauen wollte.

Dabei rückten Mittelalter und Entwicklungsländer bald überraschend nah aneinander: Auf der Basis von Modernisierungskonzepten wurde eine Parallelisierung von Außereuropa und Vormoderne vorgenommen, die das westliche Bild der Weltgeschichte seitdem prägt. Diese Gleichsetzung war um die Mitte des 20. Jahrhunderts nicht neu - wie Dipesh Chakrabarty in seiner Kritik eurozentrischer Geschichtsschreibung richtig bemerkt, hatten schon Hegel und Marx die nichtwestlichen Gesellschaften in den „Warteraum der Geschichte“ verbannt ${ }^{39}$. Die kolonialen Autoritäten hatten seit der Wende zum 19. Jahrhundert geschichtsphilosophische Entwicklungskonzepte aufgegriffen, um den Kolonien die lokal permanent geforderte Egalität und politische Partizipation zwar grundsätzlich in Aussicht zu stellen, unter Hinweis auf fehlende Modernität aber gleichzeitig in ein temporal unbestimmtes 'noch nicht' zu verschieben.

Diese Argumentationsfigur einer verspäteten Modernität ist mittlerweile von verschiedenen Seiten als Machtinstrument identifiziert worden. Man kann etwa mit Kathleen Davis von einer 'Zeitpolitik' sprechen ${ }^{40}$. Sie wirkte nach dem Ende der Kolonialreiche fort, indem sie die Verflochtenheit Europas mit der Welt ausblendete und so den konkreten wirtschaftlichen und politischen Hintergrund scheinbarer Entwicklungsunterschiede verwischte. Man erklärte die politisch und wirtschaftlich zumeist desolate Lage der ehemaligen Kolonien nicht geopolitisch, sondern historisch

38 Vgl. zuletzt WOLFGANG KNÖBL, Aufstieg und Fall der Modernisierungstheorie und des säkularen Bildes moderner Gesellschaften, in: WiLleMS u. a. (Hgg.), Moderne und Religion (wie Anm. 8) S. 75 116.

${ }^{39}$ Vgl. Dipesh Chakrabarty, Provincializing Europe. Postcolonial Thought and Historical Difference, Princeton - Oxford 22008, besonders S. 6-16, zuletzt DERS., Verspätung und Modernität: Subalterne Historien, wieder mal, in: Willems u. a. (Hgg.), Moderne und Religion (wie Anm. 8) S. 183-202. Zur Rezeption Hegels in der Betrachtung Außereuropas vgl. auch HEINZ DIETER KITTSTEINER, Hegels Eurozentrismus in globaler Perspektive, in: WolfGang HARDTWIG - PhILIPP MÜller (Hgg.), Die Vergangenheit der Weltgeschichte. Universalhistorisches Denken in Berlin, 1800-1933, Göttingen 2010, S. 50-73, und demnächst ANTJE FLÜCHTER, Die Vielfalt der Bilder und die eine Wahrheit. Die Staatlichkeit Indiens in der deutschsprachigen Wahrnehmung (1500-1700), Habilitationsschrift Heidelberg 2012 (in Druckvorbereitung).

40 Vgl. KATHLEEN DAVIS, Periodization and Sovereignty: How Ideas of Feudalism and Secularization Govern the Politics of Time, Philadelphia 2008; DIES., The Sense of an Epoch. Periodization, Sovereignty, and the Limits of Secularization, in: ANDREW COLE - D. VANCE SMITH (Hgg.), The Legitimacy of the Middle Ages. On the Unwritten History of Theory, Durham (NC) 2010, S. 39-69. 
und glaubte, dass sie sozusagen einen sehr weiten Rückstand aufzuholen hätten. Diese Annahme wird heute ausdrücklich bestritten, da man die 'great divergence', das wirtschaftliche und politische Auseinanderdriften zwischen Europa beziehungsweise dem Westen und dem Rest der Welt zumeist erst ins 18. Jahrhundert datiert. Die Wende zur Moderne glaubte man aber im Europa der 1950er bis 1970er Jahre bereits in das Hochmittelalter datieren $\mathrm{zu}$ müssen, was ältere Postulate der Geschichtsphilosophie des 19. Jahrhunderts nunmehr wissenschaftlich fundierte ${ }^{41}$.

Der Mediävistik der 1950er bis 1970er Jahre darf man nun nicht ohne Weiteres einen bewussten Willen zum 'Geschichtsraub' an den Entwicklungsländern des 20. Jahrhunderts unterstellen ${ }^{42}$. Doch viele Mittelalterhistoriker dieser Zeit interessierten sich so intensiv für die Entwicklungen ihrer Gegenwart, dass sie dennoch zur Verstetigung eines ahistorischen und asymmetrischen Vergleichs zwischen europäischer Vormoderne und außereuropäischer Gegenwart beitrugen. In Princeton reflektierte etwa Joseph R. Strayer ( $†$ 1987), Schüler des politisch ebenfalls sehr interessierten Charles Homer Haskins, über entwicklungspolitische Themen wie die

${ }^{41}$ Das Thema wird durchaus kontrovers und teils offen ideologisch diskutiert. Die späte Datierung der Divergenz zwischen Europa und dem Rest der Welt vor allem im Anschluss an KENNETH Pomeranz, The Great Divergence. China, Europe, and the Making of the Modern World Economy, Princeton (NJ) 2000. Vgl. resümierend über die Debatte PATRICK O'BRIEN, Ten Years of Debate on the Origins of the Great Divergence, (Institute of Historical Research [IHR] review no. 1008), http://www.history.ac.uk/reviews/review/1008 (letzter Zugriff 15. 9. 2013) sowie verschiedene Beiträge in OSTERHAMmel (Hg.), Weltgeschichte (wie Anm. 16). Die innerfachliche Debatte um die great divergence kann hier nicht im Detail nachvollzogen werden. Kritik innerhalb der Globalgeschichte im engeren Sinne behält zumeist die Datierung der great divergence nach 1500 bei und nuanciert sie nur (vgl. etwa PeER VRIES, Via Peking back to Manchester: Britain, the Industrial Revolution, and China, Leiden 2003). Weiterhin wird Kritik mit Bezug auf das Mittelalter geäußert, die mir vor allem als Selbstbehauptung und Selbstvergewisserung des Westens angesichts der zunehmenden Erschütterung westlicher Hegemonie in der Welt erscheint, etwa im Falle mehrerer abwehrender Befestigungen der älteren Ansätze eines frühen Aufstiegs des Westens, die sich jedoch zumeist nicht vertieft auf neue Forschungen zu den außereuropäischen Entwicklungen einlassen. Die Bandbreite dieser letzteren Gruppe umfasst teils genuin globalgeschichtlich interessierte, solide Mediävisten wie Michael Mitterauer und Robert I. Moore, die aber zumeist nur graduelle Entwicklungsunterschiede zwischen Europa und Asien feststellen und auf zukünftige weitere Vergleiche hinarbeiten (vgl. MICHAEL MitTERAUER, Warum Europa? Mittelalterliche Grundlagen eines Sonderwegs, München 2003, und dazu kritisch LudolF KUCHENBUCH, Kontrastierter Okzident. Zu Michael Mitterauers Buch Warum Europa? Mittelalterliche Grundlagen eines Sonderwegs, in: OSTERHAMMEL [Hg.], Weltgeschichte [wie Anm. 22] S. 121-140; ROBERT I. MOORE, The Transformation of Europe as a Eurasian Phenomenon, in: JOHANN P. ARNASON - BJÖRN WITTROCK [Hgg.], Eurasian Transformations, Tenth to Thirteenth Centuries. Crystallizations, Divergences, Renaissances, Leiden u. a. 2011, S. 77-98). Sie umfasst aber auch hoch identitätspolitische Populärgeschichte wie etwa NiALl FERGUSON, Civilization. The Six Killer Apps of Western Power, London 2012, die eigentlich kaum den Namen von Populärwissenschaft verdient. $\mathrm{Zu}$ jüngeren réécritures aus nichtwestlicher Sicht vgl. ferner RANDERIA - ECKERT (Hgg.), Vom Imperialismus zum Empire (wie Anm. 16); politisch-essayistisch PANKAJ Mishra, From the Ruins of Empire. The Revolt Against the West and the Remaking of Asia, London 2012.

${ }^{42}$ Vgl. dazu JACK GOODY, The Theft of History, Cambridge (MA) 2006. 
Staatsbildung ${ }^{43}$. Strayer forschte ausführlich über die Entstehung moderner und säkularer Staatsapparate im mittelalterlichen England und Frankreich, und wendete sich dabei unter anderem an moderne ,policy-makers“44. Wiewohl er weniger stark differenzierungstheoretisch argumentierte, reagierte er auf die politische Vorstellung einer graduellen Entwicklung, die zum modernen, demokratischen und säkularen Staat hinführte, und die von zeitgenössischen nichtwestlichen Staaten sozusagen absolviert werden sollte. Anhand mittelalterlicher Beispiele gab er zu bedenken, dass die Modernisierung und insbesondere die Staatsbildung ein langer und komplizierter Prozess sei, der nicht ohne Weiteres in wenigen Dekaden nachgeholt werden könne. Auch damit erfolgte freilich eine Anordnung ganz unterschiedlich strukturierter Gemeinschaften auf einer linearen Skala zunehmender Modernisierung.

Andere Historiker schlossen sich an: Sir Richard W. Southern (†2001), führender Kopf der britischen 'Intellectual history' der Nachkriegszeit, sprang beispielsweise um 1970 auf den Zug der Modernisierungstheorie auf, nachdem er bereits in seinem frühen und bis heute vielgelesenen Buch „The Making of the Middle Ages“ von 1953 ein Aufblühen europäischer Zivilisation seit dem Hochmittelalter beschrieben hatte ${ }^{45}$. Southerns Ansätze sind äußerst fein ziseliert und von großen, linearen Entwürfen oft weit entfernt. Auch er war aber nicht abgeneigt, das christliche Mittelalter als Ursprung der westlichen Moderne darzustellen. In seinem Überblickswerk „Western society and the Church“ von 1970 beanspruchte Southern ähnlich wie auch Strayer das von amerikanischen Entwicklungstheoretikern für moderne Entwicklungsländer angestrebte Erreichen von „self-sustaining growth“ in Europa bereits für das Hochmittelalter ${ }^{46}$. Damit war ein vergleichender Ansatz etabliert, der gleichzeitig eine klare, fundierende Meistererzählung für den Aufstieg Europas in der Welt bereitstellte. Ältere Forschungen zum Investiturstreit und zur Freisetzung von Politik und Recht im Ringen zwischen Papsttum und Kaisertum, die immer wieder aufscheinen, steuerten dafür Grundlagen bei.

Mit der Entstehung dieses Mittelalterbildes eines 'Rise of the West' vollzog sich insgesamt eine Art von Re-Entry der Unterscheidung 'vormodern/modern' in die Geschichte: Durch die Teilung in ein unmodernes und ein sich modernisierendes Mittelalter erschien nun nur noch das Frühmittelalter als Epoche einer undifferenzierten und religiösen Einheitswelt. Das bewirkte eine Fragmentierung der

43 Vgl. William CheSter JORDan, Foreword to the Princeton Classical Edition: Medieval Origins, in: Joseph R. Strayer, On the Medieval Origins of the Modern State, Princeton (NJ) 2005, S. xix-xxv, besonders S. xxi-xxii.

${ }^{44}$ Vgl. neben STRAYER, On the Medieval Origins (wie Anm. 43) auch Ders., Medieval Statecraft and the Perspectives of History. Essays, Princeton (NJ) 1971, besonders S. 341-348 („The Historical Experience of Nation-Building in Medieval Europe“, ursprünglich 1963); S. 251-265 („The Laicization of French and English Society in the Thirteenth Century“, usprünglich 1938).

45 Vgl. Richard W. SOUtherN, The Making of the Middle Ages, London u. a. 1953; Ders., Medieval humanism and other studies, Oxford 1970.

46 Vgl. RiCHARD W. SOUTHERN, Western Society and the Church in the Middle Ages, Harmondsworth 1970, S. 34-35. Vgl. im Vergleich KNÖBL, Aufstieg und Fall (wie Anm. 38) S. 87. 
Vormoderne-Forschung: Die 'archaisierten' Frühmittelalterhistoriker konnten sich gegen ihre Marginalisierung kaum wehren. Sie zogen sich auf ihr eigenes, in der Folge dafür schnell internationalisiertes Spielfeld zurück ${ }^{47}$. Andererseits verteidigte die Neuzeitgeschichte die Überzeugung, dass die Modernisierung Europas so recht erst mit der Neuzeit beginne. Tatsächlich dürfte die Rezeption von Modernisierungstheorien nicht nur die Hochmittelalterforschung beflügelt haben, sondern führte mit zur Konsolidierung der Disziplin der Geschichte der Frühen Neuzeit, deren Forschungsfragen bis heute außerordentlich stark von Modernisierungsannahmen und Prozesskategorien wie Sozialdisziplinierung, Konfessionalisierung und Bürokratisierung beziehungsweise Staatsbildung geprägt sind ${ }^{48}$. Wie zuletzt aus dem Fach kritisch zusammengefasst wurde, führte die Orientierung an klassischen Modernisierungskonzepten in der älteren Forschung aber häufig zu einer teleologischen Betrachtungsweise, die auf Kontrastierung von mittelalterlich und modern setzte, Transformationen rein funktionalistisch ex post erklärte, Konflikte und Alternativen ausblendete und zumeist Modernisierungsprozesse von oben annahm. Man projizierte also letztlich eine Implementation von Modernisierung durch Eliten in die Geschichte hinein, die den Planungsbemühungen der amerikanischen Entwicklungshelfer der 1950er und 1960er Jahre zum Teil verblüffend ähnelte ${ }^{49}$.

Innerhalb des Kontinuums der Geschichtsforschung konnten so Historiker bestimmter Epochen mehr mit dem Modernisierungsparadigma anfangen als andere. Als Resultat wurde die Geschichtsforschung sozusagen ungleichmäßig mit Modernisierungsannahmen durchsetzt. $\mathrm{Zu}$ den älteren Prozesskategorien wie Rationalisierung und Säkularisierung (beziehungsweise Verwissenschaftlichung) und bürokratisierender Staatsbildung traten dabei insbesondere Fragen nach Individualisierung und Verrechtlichung. Spätestens hier dürfte die Erklärung der Tatsache liegen, dass bei Vorträgen über einschlägige Themen fast unweigerlich die Frage gestellt wird, ob es das Phänomen nicht auch schon im Mittelalter (oder wahlweise: Hoch- oder Frühmittelalter, in der Antike etc.) gegeben habe. Einige Prozessbegriffe erweisen sich als so verbreitet und diffus, dass momentan vor ihrer Verwendung gewarnt wird ${ }^{50}$. Neben der 'Rationalisierung' betrifft dies, wie Alexandra

47 Vgl. zum Wandel der Wahrnehmung des Frühmittelalters die differenzierteren Überlegungen von WALTER POHL, Ursprungserzählungen und Gegenbilder. Das Frühmittelalter, in: REXROTH (Hg.), Meistererzählungen (wie Anm. 3) S. 23-42

48 Vgl. beispielhaft Rudolf Vierhaus (Hg.), Frühe Neuzeit - Frühe Moderne? Forschungen zur Vielschichtigkeit von Übergangsprozessen (Veröffentlichungen des Max-Planck-Instituts für Geschichte 104) Göttingen 1992; WOLFGANG REINHART, Sozialdisziplinierung Konfessionalisierung - Modernisierung. Ein historiographischer Diskurs, in: NADA BOSKOVSKALEINGRUBER (Hg.), Die Frühe Neuzeit in der Geschichtswissenschaft. Forschungserträge und Forschungstendenzen, Paderborn 1997, S. 39-56.

49 Vgl. Garthine Walker, Modernization, in: Dies. (Hg.), Writing Early Modern History, London 2005, S. 25-48.

50 Resultat intensiver Diskussion scheint zu sein, dass Prozesskategorien zwar unentbehrlich, einige Prozessbegriffe aber gefährlich sind, da sie nicht ausreichend operationalisierbar sind oder (wie 
Walsham herausgestellt hat, etwa die Begriffe der 'Reform/Reformation', der 'Entzauberung' oder etwa der 'Christianisierung', die sowohl in der Antike, in der Spätantike, im Früh- und Hochmittelalter sowie in der Frühen Neuzeit stattgefunden haben soll ${ }^{51}$.

\section{ALTERNATIVE ERZÄHLUNGEN: SAKRALISIERUNG UND DESAKRALISIERUNG, DIVERSIFIZIERUNG UND VERFLECHTUNG AUF DEM RELIGIÖSEN FELD}

Seit den 1970er und 1980er Jahren wurden die differenzierungstheoretischen Verlaufserzählungen aus den älteren historischen Arbeiten vor allem in anderen Fächern fortgeschrieben. Einen bis heute wichtigen Hintergrund für Theorieentwürfe bieten besonders rechtswissenschaftliche Studien. Der Staatsrechtler Ernst-Wolfgang Böckenförde wendete beispielsweise mit seinem Aufsatz zur „Entstehung des Staates als Vorgang der Säkularisation“ von 1964 auf den Spuren Max Webers den Zerfall der Einheit von Staat und Kirche ins Positive und erklärte ihn als Ursprung der Entstehung des modernen Staates. Er bezog sich nicht nur auf Hegel und Marx, sondern auch auf Leopold von Ranke und Wilhelm Dilthey, auf den Verfassungsrechtler Gerhard Anschütz zur Religionsfreiheit, auf Carl Schmitt und seine Vorstellungen von Säkularisierung und politischer Theologie, schließlich auf Ergebnisse diverser Mittelalterforscher, etwa Otto Brunners zur Entstehung moderner Herrschaftsformen im Mittelalter ${ }^{52}$. Äußerst populär wurde aber auch das Buch „Law and Revolution. The Formation of the Western Legal Tradition“, das der amerikanische Rechtshistoriker Harold J. Berman erst 1983 vorlegte. Er rezipierte vor allem die historische Erzählung Ullmanns vom Wachstum der päpstlichen Herrschaft, aber auch Southern und Strayer, und setzte aus ihren differenzierteren Ergebnissen ein Narrativ der gregorianischen 'Revolution' des Rechts zusammen ${ }^{53}$. Er sah wie

'Modernisierung') getrennte Prozesse unzulässig zusammenfassen. Vgl. JOAS, Gefährliche Prozessbegriffe (wie Anm. 9); VOLKHARD KRECH, Über Sinn und Unsinn religionsgeschichtlicher Prozessbegriffe, in: GABRIEL - GÄRTNER - POLLACK (Hgg.), Umstrittene Säkularisierung (wie Anm. 4) S. 565-603; Barbara Stollberg-Rilinger, Die Frühe Neuzeit - eine Epoche der Formalisierung?, in: ANDREAS HÖFELE - JAN-DIRK MÜLLER - WulF OESTERREICHER (Hgg.), Die Frühe Neuzeit - Revisionen einer Epoche (Pluralisierung und Autorität 40) Berlin 2013, S. 3-28, besonders S. 3-4.

${ }^{51}$ Vgl. Walsham, Migrations of the Holy (wie Anm. 15) Kapitel III.

52 Vgl. ERNST-WOLFGANG BÖCKENFÖRDE, Die Entstehung des Staates als Vorgang der Säkularisation, in: DERS., Recht, Staat, Geschichte: Studien zur Rechtsphilosophie, Staatstheorie und Verfassungsgeschichte, Frankfurt a. M. 1991, S. 92-114.

53 Vgl. Harold J. Berman, Law and Revolution. The Formation of the Western Legal Tradition, Cambridge (MA) 1983. Zur Kritik an Berman vgl. die Literaturverweise in STECKEL, Säkularisierung (wie Anm. 11) S. 167 Anm. 61, sowie exemplarisch Kenneth Pennington, Review: Harold J. Berman, Law and Revolution. The Formation of the Western Legal Tradition, Cambridge (MA) 1983, in: The American Journal of Comparative Law 33/3, 1985, S. 546-548; RudOLF SCHIEFFER, 'The Papal Revolution in Law?' Rückfragen an Harold Berman, in: Bulletin of Medieval Canon Law NS 22, 1998, S. 19-30. 
Böckenförde und die älteren Historiker den Streit zwischen Papst und Kaiser als produktive Freisetzung von geistlich und weltlich. Er machte jedoch vor allem das Papsttum zum Ausgangspunkt für eine Modernisierungserzählung, nach der ein neues, wissenschaftlicheres Recht auf Initiative des Papsttums in ganz Europa implementiert worden sei. Seine inhaltlich heute überholte und oft fehlerhafte Darstellung scheint besonders innerhalb der Rechtswissenschaft rezipiert worden zu sein. Sie wurde etwa von Luhmann in seinem „Recht der Gesellschaft“ von 1993 benutzt ${ }^{54}$.

Innerhalb weiter Teile der Mittelaltergeschichte wurden die typischen modernisierungstheoretischen Forschungsfragen, besonders zur Entstehung des Staates, in dieser Zeit und bis in die letzten Jahre hinein dagegen abgewandelt. Wiederum sehr knapp nachgezeichnet, verlagerten sich mit der zunehmenden Internationalisierung der Forschung die Interessen ${ }^{55}$ : Bis zum 2. Weltkrieg und in der Nachkriegszeit waren Theorien gesellschaftlicher Differenzierung und Modernisierung in noch weitgehend national strukturierten Fachkulturen rezipiert worden, die sich erst langsam vom nationalen Konkurrenzdenken des 19. und frühen 20. Jahrhunderts lösten. Seit der Nachkriegszeit strebte man dann gerade mit der Rezeption modernisierungstheoretischer Modelle stärker nach einer Überwindung nationalgeschichtlicher Paradigmen. Erst seit den 1970er Jahren kamen aber verstärkt globalgeschichtlich und innereuropäisch vergleichende Ansätze auf. Sie förderten vielfach Befunde zu Tage, die dem erwarteten Verlaufsschema von Modernisierung und Differenzierung nicht entsprachen. Parallel zu ähnlichen Fragen in der Entwicklungspolitik begann man auch in der Geschichtswissenschaft zu überlegen, ob es einen 'Normalweg' der Modernisierung überhaupt gebe. In Deutschland stritt man etwa um den deutschen 'Sonderweg' in die Moderne im 19. und 20. Jahrhundert ${ }^{56}$. In der Globalgeschichte sowie in der britischen und bald auch internationalen

\footnotetext{
${ }^{54}$ Vgl. NikLas Luhmann, Das Recht der Gesellschaft, Frankfurt a. M. 1993, S. 263-265. Als weiteren Bezug auf Berman an prominenter Stelle vgl. HORST DREIER, Kanonistik und Konfessionalisierung. Marksteine auf dem Weg zum Staat, in: GEORG SIEBECK (Hg.), Artibus ingenuis. Beiträge zu Theologie, Philosophie, Jurisprudenz und Ökonomik, Tübingen 2001, S. 133-169, besonders S. $142-$ 147.

$55 \mathrm{Zu}$ diesen Entwicklungen sei hier nur genannt JÜRGEN OSTERHAMMEL (Hg.), Geschichtswissenschaft jenseits des Nationalstaats. Studien zu Beziehungsgeschichte und Zivilisationsvergleich (Kritische Studien zur Geschichtswissenschaft 147) Göttingen 2001; HEINZ-GERHARD HAUPT - JÜRGEN KOCKA (Hgg.), Geschichte und Vergleich. Ansätze und Ergebnisse international vergleichender Geschichtsschreibung, New York - Frankfurt a. M. 1996; für die Mediävistik vgl. PATRICK J. GEARY, „Multiple Middle Ages“ - konkurrierende Meistererzählungen und der Wettstreit um die Deutung der Vergangenheit, in: REXROTH (Hg.), Meistererzählungen (wie Anm. 3) S. 107-120; WOLFRAM DrEWS, Transkulturelle Perspektiven in der mittelalterlichen Historiographie. Zur Diskussion welt- und globalgeschichtlicher Entwürfe in der aktuellen Geschichtswissenschaft, in: Historische Zeitschrift 292, 2011, S. 31-59, besonders S. 33-40.

56 Vgl. JÜRGEN KOCKA, Asymmetrical historical comparison: The Case of the German Sonderweg, in: History and Theory 38/1, 1999, S. 40-50.
} 
Mediävistik wurde heftig um die Vergleichbarkeit globaler und europäischer Feudalismen gerungen ${ }^{57}$.

Die identitätspolitische Problematik der Modernisierungsansätze wurde nicht zuletzt in der deutschen Mediävistik spürbar, denn das mittelalterliche Reich fand sich, sobald man den Investiturstreit einmal hinter sich ließ, in der Position eines Modernisierungsverlierers wieder: In der anglophonen und frankophonen Forschung der Nachkriegszeit verfolgte man den Aufstieg der westeuropäischen Monarchien Frankreich und England als Normalfall hochmittelalterlicher Modernisierung. Zwar bemühte man noch die ältere, aus der deutschsprachigen Forschung rezipierte Erzählung der Aufspaltung der Einheit von Reich und Kirche im Investiturstreit, da sie einen Anfangspunkt und bequemen 'Aufhänger' für weitere Modernisierungserzählungen bot ${ }^{58}$. Doch das Reich sowie Ost- und teils Südeuropa erschienen ansonsten als Abweichung vom Pfad der Moderne. Die Entwicklung des römisch-deutschen Reichs im Hochmittelalter passte schon deswegen nicht in das Muster, da keine starke, zentrale Monarchie entstand. Im Bereich der Geistesgeschichte musste man zugeben, dass im Reich nördlich der Alpen vor Prag 1348 keine Universität gegründet wurde. Man konnte also in politischer wie intellektueller Hinsicht nur eine 'verspätete Modernisierung' konstatieren, und begann intensiv zu fragen, warum das Reich die entsprechenden Phänomene nicht von allein entwickelte oder aus dem Westen übernahm ${ }^{59}$. Mit dem Postulat einer Modernisierung seit dem Hochmittelalter, so scheint es aus heutiger Perspektive, hatte man letztlich auch die Unterscheidung zwischen kulturell aktivem Westen und passiv rezipierendem Nichtwesten rekursiv in das europäische Mittelalter eingeführt.

Erwartungsgemäß wandten die betroffenen akademischen Milieus sich bald vom klassischen Modernisierungsparadigma ab oder begannen, es kritisch zu adaptieren. Viele Ansätze innerhalb der deutschen und internationalen Mediävistik der letzten Jahre bezogen sehr wichtige Anregungen aus dieser kritischen Auseinandersetzung, wobei oft auch Denkanstöße aus anderen Epochendisziplinen und Fächern

${ }^{57}$ Vgl. als Resümee Elizabeth A. R. BROWN, The Tyranny of a Construct: Feudalism and Historians of Medieval Europe, in: LeSTER K. LiTTLE - BARbARA H. Rosenwein (Hgg.), Debating the Middle Ages. Issues and Readings, London 1998, S. 148-169.

58 Vgl. STRAYER, On the Medieval Origins (wie Anm. 43) S. 20-22, mit Verweis auf Tellenbach, Ullmann (wie Anm. 11) und weitere ältere Forschungen.

$59 \mathrm{Vgl}$. insbesondere TIMOTHY REUTER, Nur im Westen was Neues? Das Werden prämoderner Staatsformen im europäischen Hochmittelalter, in: JOACHIM EHLERS (Hg.), Deutschland und der Westen Europas im Mittelalter (Vorträge und Forschungen 56) Stuttgart 2002, S. 327-351; DERS., The Medieval German Sonderweg? The Empire and its Rulers in the High Middle Ages, in: ANNE J. DugGan (Hg.), Kings and Kingship in Medieval Europe (King's College London Medieval Studies 10) London 1993, S. 179-211; insgesamt auch EHLERS (Hg.), Deutschland und der Westen. Vgl. aber auch schon frühere beziehungsgeschichtliche Arbeiten wie PETER CLASSEN, Zur Geschichte der Frühscholastik in Österreich und Bayern, in: DERS., Ausgewählte Aufsätze, hg. von JOSEF FLECKENSTEIN mit CARL JOACHIM CLASSEN und JOHANNES FRIED (Vorträge und Forschungen 28) Sigmaringen 1983, S. 279-306 (ursprünglich 1959). 
aufgenommen wurden ${ }^{60}$. Allein in der Erforschung politischer Ordnungen hat sich dabei das Blickfeld sehr stark ausgeweitet.

Einerseits ist in verschiedenen vergleichenden Arbeiten deutlich geworden, wie vielfältig die Gestaltung politischer Ordnungen innerhalb Europas seit dem Hochmittelalter war und welche Verknüpfungen zwischen regionalen Entwicklungen bestanden ${ }^{61}$. Schon allein der Vergleich des Reichs, Westeuropas und der skandinavischen und iberischen Monarchien zeigt eine große Bandbreite von Verknüpfungen des Religiösen und Politischen ${ }^{62}$. Über die Päpste und Könige hinaus haben neuere Forschungen längst auch weitere politische Akteure einbezogen, nicht zuletzt die Städte mit ihren zumeist im Kern weltlichen conjurationes und Gilden, auf die bereits Oexle hinwies ${ }^{63}$. Neuerdings werden vergleichende Ansätze in Richtung transkultureller Perspektiven ausgebaut, so dass deutlicher ins Blickfeld tritt, dass vergleichbare oder verwandte Konzepte monarchischer Herrschaft und religiöser oder

${ }^{60}$ Ein wichtiger Anstoß ging auch von der Rezeption anthropologischer Ansätze aus, die nicht zuletzt über die frankophone Forschung erfolgte. Wie PAUL FrEEDMAN - GABRIELLE M. SPIEGEL, Medievalisms Old and New. The Rediscovery of Alterity in North American Medieval Studies, in: The American Historical Review 103/3, 1998, S. 677-704, für die amerikanische Forschung konstatiert haben, führte dies jedoch teils zu einem unverbundenen Nebeneinander von modernisierungstheoretischen Verlaufserzählungen und anthropologisch inspirierten Zustandsbeschreibungen mittelalterlicher Phänomene; die eine Richtung postulierte Identität von Moderne und Mittelalter, während die andere Seite gerade die Alterität des Mittelalters betonte.

${ }^{61}$ Mit Hinweisen auf gesamteuropäische Verflechtungen schon REUTER, Nur im Westen was Neues (wie Anm. 59) S. 344-346; vgl. ansonsten EHLERS (Hg.), Deutschland und der Westen (wie Anm. 59); CARLRICHARD BRÜHL - BERND SCHNEIDMÜLLER (Hgg.), Beiträge zur mittelalterlichen Reichs- und Nationsbildung in Deutschland und Frankreich (Historische Zeitschrift. Beihefte NF 24) München

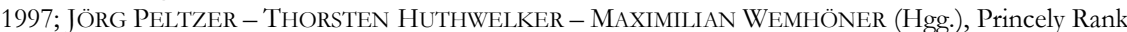
in late Medieval Europe. Trodden Paths and Promising Avenues (RANK. Politisch-soziale Ordnungen im mittelalterlichen Europa 1) Ostfildern 2011; SverRe BAGGE (Hg.), Statebuilding in Medieval Norway, o.O. 1989; BJÖRN WEILER, Kingship, Rebellion and Political Culture: England and Germany, c. 1215 - c. 1250, London 22011. Stärker beziehungsgeschichtlich MARTIN KINTZINGER, Westbindungen im spätmittelalterlichen Europa. Auswärtige Politik zwischen dem Reich, Burgund und England in der Regierungszeit Kaiser Sigismunds (Mittelalter-Forschungen 2) Stuttgart 1999; BJÖRN WEILER, Henry III and the Staufen Empire; 1216-1272 (Royal Historical Society Studies in History) Woodbridge 2006.

${ }^{62}$ Vgl. etwa die Ansätze in BERND SCHNEIDMÜLLER, Grenzerfahrung und monarchische Ordnung. Europa 1200-1500 (C. H. Beck Geschichte Europas) München 2011; WALTER POHL - VERONIKA WIESER (Hgg.), Der frühmittelalterliche Staat. Europäische Perspektive (Forschungen zur Geschichte des Mittelalters 16) Wien 2009; Thomas F. X. NOBLE - JOHN VAN EngEN (Hgg.), European Transformations. The Long Twelfth Century, Notre Dame (IN) 2012, besonders die Beiträge von Adam J. Kosto, Sverre Bagge und Piotr Gorecki; Ludger KÖRNTGEN - DOMINIK WAßENHOVEN (Hgg.), Religion und Politik im Mittelalter. Deutschland und England im Vergleich (Prinz-AlbertStudien 29) Berlin - New York 2013.

${ }^{63}$ Vgl. mit Verweisen OTTO Gerhard OeXle, Dauer und Wandel religiöser Denkformen, Praktiken und Sozialformen im mittelalterlichen Europa, in: KIPPENBERG - RÜPKE - VON STUCKRAD (Hgg.), Europäische Religionsgeschichte (wie Anm. 9) 1, S. 155-192. 
profaner Herrschaftslegitimation im christlichen und islamischen Raum (sowie darüber hinaus) auftreten und einander beeinflussen ${ }^{64}$.

Schließlich hat sich der Blick in methodischer Hinsicht über die alten Themen der Staatsbildung wie Bürokratisierung und Verrechtlichung zu einer Kulturgeschichte des Politischen erweitert ${ }^{65}$. Politik konnte man im Mittelalter auch im Rahmen plurimedialer kultureller Symbolisierungen und ungeschriebener gruppenbildender Spielregeln institutionell festigen, was von der älteren Forschung nur zum Teil einbezogen wurde ${ }^{66}$. Wenn man die bildlichen, symbolischen, performativ-praktischen und argumentativen Haushalte politischer, religiöser oder rechtlicher Ordnungen mit einbezieht, lassen sich zudem Verschiebungen und Verknüpfungen zwischen gesellschaftlichen Sphären sehr viel deutlicher darstellen, also sozusagen Verflechtungen auf konzeptueller Ebene.

Die Frage nach dem Verhältnis und der Differenzierung von Religion und Politik ist von den erwähnten neueren Forschungen freilich nicht als zentrale Frage verfolgt worden. Sie wurde typischerweise noch im Rahmen der älteren Forschungsansätze diskutiert, die den Aufstieg moderner Staatlichkeit verfolgten und daher auf die Trennung geistlicher und weltlicher Gewalt fokussierten. Auf dem mittlerweile sehr viel genauer bekannten und komplexer gewordenen Forschungsfeld könnte man mit der Frage nach der Differenzierung von Religion und Politik und nach deren Verknüpfung aber momentan auch andere, neuen Fragestellungen verpflichtete Entwicklungslinien ziehen. Dass eine ganze Bandbreite unterschiedlicher Zugänge möglich ist, möchte ich an einer Diskussion der Ansätze Detlef Pollacks und möglicher Alternativen zeigen.

${ }^{64}$ Vgl. WOLfram Drews - Jenny RAHel OeSterle (Hgg.), Transkulturelle Komparatistik. Beiträge zu einer Globalgeschichte der Vormoderne, Leipzig 2008; JENNY RAHEL OESTERLE, Kalif und König. Herrschaftsrepräsentation der Fatimiden, Ottonen und frühen Salier an religiösen Hochfesten (Symbolische Kommunikation in der Vormoderne. Studien zur Geschichte, Literatur und Kunst) Darmstadt 2009; WOLFRAM DREWS, Die Karolinger und die Abbasiden von Bagdad. Legitimationsstrategien frühmittelalterlicher Herrscherdynastien im transkulturellen Vergleich, Berlin 2009; demnächst STEFAN BURKHARDT, Mediterranes Kaisertum und imperiale Ordnungen. Das lateinische Kaiserreich von Konstantinopel, Habilitationsschrift Heidelberg 2012 (in Druckvorbereitung); FLÜCHTER - RICHTER (Hgg.), Structures on the Move (wie Anm. 22).

65 Vgl. BARBARA STOLlBerg-RILINGER, Was heißt Kulturgeschichte des Politischen? (Zeitschrift für Historische Forschung Beihefte 35) Berlin 2005; vgl. aber auch schon GERD ALTHOFF, Die Ottonen. Königsherrschaft ohne Staat, Stuttgart u. a. 22005.

${ }^{66}$ Vgl. die verschiedenen Ansätze in GERD ALTHOFF, Die Macht der Rituale. Symbolik und Herrschaft im Mittelalter, Darmstadt 2003; GEOFFrEY KOZIOL, Begging Pardon and Favour. Ritual and Political Order in Early Medieval France, Ithaca (NY) 22011; allgemein CHRISTIANE BROSIUS - AXEL Michaels - PAula SCHRode (Hgg.), Ritual und Ritualdynamik. Schlüsselbegriffe, Theorien, Diskussionen (UTB 3854) Göttingen 2013; aber auch institutionentheoretisch/-historisch KARLSIEGBERT REHBERG, Weltrepräsentanz und Verkörperung. Institutionelle Analyse und Symboltheorien - Eine Einführung in systematischer Absicht, in: GERT MELVILLE (Hg.), Institutionalität und Symbolisierung. Verstetigungen kultureller Ordnungsmuster in Vergangenheit und Gegenwart, Köln u. a. 2001, S. 3-52; GERT Melville - HANS VORLÄNder (Hgg.), Geltungsgeschichten. Über die Stabilisierung und Legitimierung institutioneller Ordnungen, Köln u. a. 2002. 
Pollack untersucht aus einer akteursorientierten Perspektive die Konfliktschübe, die maßgeblich durch den Anspruch des Papstes auf Überordnung über die weltlichen Herrscher vom 11. bis 13. Jahrhundert ausgelöst wurden. In ihnen musste die angezweifelte Legitimität der laikalen Herrschaft sozusagen auf neue Füße gestellt werden, was zum Teil durch Rückgriff auf profane Begründungsressourcen geschah. Pollack konstatiert daher die „Differenzierung“ einer weltlich gedachten Politik als „abgrenzende Reaktion“ auf den Versuch einer „Entdifferenzierung“ durch das Papsttum $^{67}$. Als Rahmen dieser Überlegung nimmt Pollack an, dass im Frühmittelalter trotz teils vorhandener Konzepte gesellschaftlicher funktionaler Differenzierung (wie dem Drei-Stände-Schema) keine systemische funktionale Differenzierung anzutreffen sei. Dabei nimmt er Rudolf Stichwehs Unterscheidung situativer, rollenmäßiger oder systemischer Differenzierung auf ${ }^{68}$. In einer mehrschrittigen Analysekette untersucht Pollack insgesamt den „Angriff“ des Papsttums auf das Königtum im Investiturstreit, seine eruierbaren Motive, Gegeninitiativen des Königtums, erneute Initiativen des Papsttums, schließlich die Verdichtungen neuer Begründungen weltlicher Herrschaft im 12. und 13. Jahrhundert. Zu Beginn des 14. Jahrhunderts sieht er die in den Konflikten ständig reformulierten neuen Semantiken um die Themen der geistlichen und weltlichen Herrschaft so weit verdichtet, dass man von einer funktionalen Differenzierung dieser Bereiche sprechen könne: „Am Ende aber steht das Auseinanderfallen der Herrschaftsbereiche, deren Codes und Legitimationsformeln nicht mehr vermittelbar sind. Die Differenzierung von Religion und Politik ist so der nicht intendierte Effekt von Dedifferenzierungsanstrengungen, die einander ausschließen." 69

\footnotetext{
67 Zum unterliegenden Konzept von Differenzierung und Entdifferenzierung vgl. auch DETLEF POLLACK, Differenzierung und Entdifferenzierung, in: GABRIEL - GÄRTNER - POLLACK (Hgg.), Umstrittene Säkularisierung (wie Anm. 4) S. 545-564; zur soziologischen Diskussion auch DIETRICH RÜSCHEMEYER, Über Entdifferenzierung, in: WOLFGANG GLATZER (Hgg.), 25. Deutscher Soziologentag. Die Modernisierung moderner Gesellschaften, Opladen, 1991, S. 378-381; FRANK J. LECHNER, Fundamentalism and Sociocultural Revitalization. On the Logic of Dedifferentiation, in: Jeffrey C. Alexander - Paul Burbank Colomy (Hgg.), Differentiation Theory and Social Change: Comparative and Historical Perspectives, New York 1990, S. 88-118.

68 Vgl. Pollack, Die Genese (wie Anm. 4) mit Bezug auf Rudolf STICHWEH, Soziologische Differenzierungstheorie als Theorie sozialen Wandels, in: JÜRGEN MIETHKE - KLAUS SCHREINER (Hgg.), Sozialer Wandel im Mittelalter: Wahrnehmungsformen, Erklärungsmuster, Regelungsmechanismen, Sigmaringen 1994, S. 29-43, S. 38: „Zwar lassen sich in vormodernen Gesellschaften Formen einer situationalen und rollenmäßigen Differenzierung finden, nicht aber Formen einer systemischen Differenzierung. [...] Mit situationaler Differenzierung bezeichnet Rudolf Stichweh (1994: 38) die situative Ausdifferenzierung von funktionalen Spezifikationen, die für eine bestimmte Situation vorgenommen und nach einer gewissen Zeit wieder aufgegeben wird; Rollendifferenzierung meint die Ausdifferenzierung bestimmter Rollen für eingegrenzte Handlungsvollzüge, zum Beispiel die Ausdifferenzierung von Priesterrollen; von systemischer Differenzierung ist zu sprechen, wenn eine Funktion ausdifferenziert wird und Inklusion in das dadurch entstehende Funktionssystem nicht nur über Rollenträger, sondern auch durch komplementäre Publikumsrollen, somit also potentiell für jedermann garantiert ist.“

${ }^{69}$ Pollack, Die Genese (wie Anm. 4) bei Anm. 110.
} 
Dieser Zugang revidiert die älteren, modernisierungstheoretischen Verlaufserzählungen in Teilen und fragt neu nach der Entstehung übergreifender Strukturen. Pollack stellt dazu Konfliktschübe in den Vordergrund, die zumeist zu expliziten (Re-)Formulierungen konkurrierender Ordnungsvorstellungen führten. Er geht zudem von schrittweisen Entwicklungen aus - im diskutierten Fall von Prozessen, die sich sogar vom 11. bis ins 14. Jahrhundert hinziehen.

Äußerst wichtig erscheint auch sein Ansatz, nicht nur Politik und Religion, sondern auch andere Bereiche wie das Recht einzubeziehen und dabei auf das Zusammenspiel bildlicher und symbolischer Kommunikation zurückzugreifen. Dadurch geraten Momente des kulturellen Transfers in den Blick, die Pollack als „integrative oder synthetisierende Praktiken“ beschreibt. Wie er im Anschluss an Gerhard Dilcher argumentiert, bewirkten die Konfliktkonstellationen zwischen Kaiser und Papst beispielsweise kulturelle Pluralisierung: Unter dem Druck fehlender kirchlicher Legitimation griffen Kaiser wie Friedrich I. und Friedrich II. nicht nur auf historische, religiöse und rechtliche Legitimationsmuster zurück ${ }^{70}$. Das kaiserliche Recht konnte, wie Dilcher am Beispiel bildlicher Darstellungen am Stadttor von Capua diskutiert, sogar sakralisiert werden, indem ein weltlicher Richter in der Symbolik einer Trinitätsdarstellung abgebildet wurde. Wie Pollack zusammenfasst: „Die Iustitia tritt damit in Konkurrenz zur christlichen Trinitätslehre und soll so offenbar die Funktion erfüllen, diese zu überbieten. In der Darstellung am Tor von Capua geht es darum, „die von der Kirche unabhängige, von Gott schöpfungsmäßig gestiftete, darum der Notwendigkeit entsprechende weltliche Gewalt“ bildlich zu legitimieren und sie „zu einer eigenen Sakralität“ zu erheben, „die es im Mittelalter zuvor nicht gab. ${ }^{671}$

Doch scheint mir die (teils ja nur implizit) vorgeschlagene Vorgehensweise insofern nicht weit genug zu gehen, als die Dynamisierung des Zugriffs auf veränderliche historische Formen der Differenzierung von Religion und Politik punktuell bleibt. Zwar erscheint eine Konsolidierung gegeneinander ausdifferenzierter Bereiche sehr früh und als historisch kontingenter Prozess - doch wird die gebotene historische Erzählung andererseits noch sehr stark vom unterliegenden älteren Narrativ eines Zerfalls der Einheit von Religion und Politik geprägt, das aus den oben diskutierten historischen Forschungen bezogen wird.

Der beschriebene Prozess einer graduellen Ausdifferenzierung könnte zukünftigen Lesern daher als bloße Variation auf das 'Rise of the West'-Mittelalter erscheinen, die man über Luhmann, Berman, Strayer, Southern und Böckenförde vor allem auf Ullmanns „Growth of Papal Government“ von 1955 zurückführen kann.

70 POLLACK, Die Genese (wie Anm. 4) bei Anm. 102-103.

71 POLlack, Die Genese (wie Anm. 4) bei Anm. 108; mit Zitat aus GERHARD DilCHER, Säkularisierung von Herrschaft durch Sakralisierung der Gerechtigkeit? Überlegungen zur Gerechtigkeitskonzeption bei Kaiser Friedrich II. und Ambrogio Lorenzetti, in: INGE KROPPENBERG - MARTIN LÖHNIG DieTER SCHWAB (Hgg.), Recht - Religion - Verfassung. Festschrift für Hans-Jürgen Becker zum 70. Geburtstag am 3. November 2009, Bielefeld 2009, S. 9-47, hier S. 22. 
Dahinter scheint nicht nur die protestantische Meistererzählung Troeltschs von der zerbrechenden Einheitswelt durch, die von der Mediävistik ins Hochmittelalter verlagert wurde. Man hört letztlich sogar mittelalterliche Stimmen, die das Zerbrechen zeitgenössischer Ordnung beklagten ${ }^{72}$. Angesichts der von neueren Forschungen herausgearbeiteten Pluralität europäischer Entwicklungen könnte man jedoch auch andere Entwicklungslinien im europäischen Mittelalter verfolgen. Wenn wir die vorhandenen theoretischen Verlaufsmuster überprüfen und flexibilisieren wollen, müssten strenggenommen zunächst auch mögliche Alternativen einbezogen werden, bevor an eine neue Theorie historischer Differenzierungsprozesse zu denken ist.

Doch sind die Ansatzpunkte dafür sehr vielfältig. Nicht nur kann man die historische Verschränkung von Religion und Politik auf anderen Feldern neben dem der Trennung von geistlicher und weltlicher Gewalt diskutieren. Man könnte gerade auf diesem Feld viele regionale Alternativen aufmachen. Wenn man die Vielfalt europäischer Entwicklungen einbezieht, tritt etwa vor Augen, dass Pollacks Verdichtung einzelner Befunde zum Bild einer zunächst undifferenzierten, dann zunehmend differenzierten weltlichen und geistlichen Herrschaft räumlich-politisch aufgeschlüsselt werden könnte: Die vielen regna und gentes des Frühmittelalters mit ihren unterschiedlichen Landeskirchen oder „Micro-Christendoms“"73 machen es schwierig, für die Zeit vor dem 11. Jahrhundert eine lineare Geschichte des Verhältnisses von geistlicher und weltlicher Gewalt zu erzählen. Pollack geht daher von fehlender Differenzierung aus. Doch das täuscht, und bestärkt möglicherweise unversehens die alte, nicht zuletzt konfessionell geprägte Vorstellung einer mittelalterlichen „Einheitswelt“. Die Geschichte des Verhältnisses von Religion und Politik im Frühmittelalter könnte man stattdessen aber als regional mehrstimmig auffassen. Aktuelle Forschungen haben zu ihr gerade neue Ergebnisse erbracht: Die Studie Gerd Althoffs in diesem Band zeigt, dass eine konzeptuelle Trennung und intensives politisches Ringen um die Überordnung von geistlicher und weltlicher Gewalt bereits in der Karolingerzeit Höhepunkte erlebten, an die dann im Investiturstreit wieder angeknüpft werden konnte. Ein Sammelband von Ludger Körntgen und Dominik Waßenhoven hat jüngst eine Vielfalt vergleichender

\footnotetext{
72 Vor einer theoretischen Modellbildung, die letztlich vormoderne Sakralgeschichte reflektiert, warnt insbesondere auch WALSHAM, Migrations of the Holy (wie Anm. 15). Einen exemplarischen Nachweis über die Nachwirkungen älterer, in diesem Falle ebenfalls protestantischer Sakralgeschichte in die neuere Religions- und Philosophiegeschichte bietet am Beispiel des Atheismus DOROTHEA WELTECKE, „Der Narr spricht: Es ist kein Gott“. Atheismus, Unglauben und Glaubenszweifel vom 12. Jahrhundert bis zur Neuzeit (Campus historische Studien 50) Frankfurt a. M. 2010.

73 Vgl. zur Vorstellung von parallelen „Micro-Christendoms“ im Frühmittelalter MAYKE DE JONG, The State of the Church. Ecclesia and Early Medieval State Formation, in: POHL -WIESER (Hgg.), Der frühmittelalterliche Staat (wie Anm. 62) S. 241-255, unter Rückgriff auf PETER BROWN, The Rise of Western Christendom: Triumph and Diversity, A.D. 200-1000, London 22003.
} 
Perspektiven auf Neuverhandlungen von Grenzen zwischen geistlichen und weltlichen politischen Akteuren im Reich und in England vorgestellt ${ }^{74}$.

Wenn man in die Zeit nach dem Investiturstreit blickt, wirkt die Erzählung der Trennung von geistlicher und weltlicher Herrschaft zunächst kohärenter. Mit dem Papsttum war nun ein überregional wirkmächtiger Akteur vorhanden, zu dem sich verschiedene politische Mächte positionieren mussten. Es ist also leichter, eine kohärente Entwicklung nachzuverfolgen, was ja auch bereits vielfach geschehen ist ${ }^{75}$. Doch auch für die zahlreichen weltlichen Herrscher des Hoch- und Spätmittelalters und ihr Verhältnis zum Papst und zum regionalen Episkopat könnte man jeweils unterschiedliche Erzählstränge aufmachen und so ein vielstimmiges Neben- und Durcheinander stärker sakralisierter und stärker profaner Begründungen von Herrschaft postulieren.

Wenn man diese Überlegungen mit einbezieht, wird deutlich, dass die um den Investiturstreit organisierte historische Erzählung nur eine von mehreren möglichen ist. Sie neigt zumeist zur Reichsgeschichte. Doch könnte man genauso gut konsequent auf Frankreich fokussieren und erhielte dann einen anderen Spannungsbogen: Die französische Kirche bildete von Beginn an ein außerordentlich wichtiges Experimentierfeld für die Kirchenreform des 11. Jahrhunderts. Französische Kleriker brachten nicht nur die bekannte Differenzierung in spiritualia und temporalia hervor, die die Investiturproblematik entschärfte ${ }^{76}$. Auch die diversen klösterlichen Reformnetzwerke in Nordfrankreich und die dort entstehenden Schullandschaften boten wichtige religiöse und intellektuelle Ressourcen für das Papsttum. Im Nachgang des Investiturstreits konnte auch der französische König von diesen Entwicklungen profitieren ${ }^{77}$. Die französischen Könige kultivierten bald schon eine eigenständige Sakralität der französischen Monarchie und eröffneten so neue Legitimationsquellen ${ }^{78}$. Daneben gewannen sie weitere Legitimation ihrer Herrschaft aus dem intensiv kultivierten Recht sowie den Wissenschaften und Künsten. Sie stellten sich über weite

${ }^{74}$ Vgl. Althoff, Differenzierung (wie Anm. 4); KÖRNTGEN - WAßENHOVEN (Hgg.), Religion und Politik (wie Anm. 62).

75 Vgl. mit Verweisen Heike Johanna Mierau, Kaiser und Papst im Mittelalter, Köln u. a. 2010; JÜRGEN MIETHKE - ARNOLD BÜHLER, Kaiser und Papst im Konflikt: zum Verhältnis von Staat und Kirche im späten Mittelalter (Historisches Seminar 8) Düsseldorf 1988.

${ }^{76} \mathrm{Vgl}$. zur Frühgeschichte der Unterscheidung OLIVIER GUILLOT, A Reform of Investiture before the Investiture Struggle in Anjou, Normandy and England, in: Haskins Society Journal 3, 1991, S. 81-100.

77 Vgl. ROLF GROßE, Frankreichs neue Überlegenheit, in: BERND SCHNEIDMÜLLER - STEFAN WeINFurTer (Hgg.), Salisches Kaisertum und neues Europa. Die Zeit Heinrichs IV. und Heinrichs V., Darmstadt 2007, S. 195-216; DERS., „La fille aînée de l'Église“: Frankreichs Kirche und die Kurie im 12. Jahrhundert, in: JOCHEN JOHRENDT - HARALD MÜLlER (Hgg.), Römisches Zentrum und kirchliche Peripherie. Das universale Papsttum als Bezugspunkt der Kirchen von den Reformpäpsten bis zu Innozenz III. (Neue Abhandlungen der Akademie der Wissenschaften zu Göttingen, Philologisch-Historische Klasse, NF 2) Berlin - New York 2008, S. 299-321.

78 Vgl. so schon Joseph R. STRAYer, France: The Holy Land, the Chosen People, and the Most Christian King, in: DERS., Medieval Statecraft (wie Anm. 44) S. 300-314; beispielhaft JACQUES LE GofF, Saint Louis, Paris 1996. 
Strecken sehr eng zum Papsttum, das sie schließlich vielfältig beeinflussten und ab dem 14. Jahrhundert teils zu kontrollieren suchten ${ }^{79}$. Ihr Einfluss auf die bevorzugte Form der Trennung von geistlich und weltlich sollte also nicht unberücksichtigt bleiben.

Doch das verschiebt sogleich die historischen Zäsuren an andere Stellen. Über das Hoch- und Spätmittelalter hinweg gab es ja nicht nur zwischen den römischdeutschen Königen, sondern auch zwischen den französischen und englischen Königen und dem Papsttum intensive Auseinandersetzungen. Sie waren längst denkbar, setzten aber teils an ganz anderen Themen an, beispielsweise an der Frage der Finanzierung der päpstlichen Aktivitäten wie etwa der Kreuzzüge ${ }^{80}$. Während es für sie wie für andere europäische Herrscher lange Zeit opportun war, eine enge Bindung an das Papsttum zu suchen, war dies in bestimmen Situationen schließlich nicht mehr der Fall. Verschiedene europäische politische Akteure propagierten also andere Formen der Verschränkung von geistlicher und weltlicher Gewalt als die hierokratische Papstkirche. Religiöse Gegenbewegungen zur Konsolidierung der römischen Kirche waren sowieso schon seit dem 12. Jahrhundert präsent und verknüpften sich teils mit politischen Konflikten ${ }^{81}$. Abweichende Ordnungsvorstellungen wie der Konziliarismus traten dann seit dem 14. Jahrhundert verstärkt auf. Spätestens mit dem 15. Jahrhundert übersetzten sich solche längst vorhandenen Tendenzen in einen sichtbaren Diversifizierungsprozess innerhalb Europas, in dem sich zunächst mit dem Hussitismus und Utraquismus in Böhmen, dann mit den verschiedenen europäischen Reformationen lokale Kirchen und Konfessionen etablierten. Die Verschränkung zwischen politischer Herrschaft und religiöser Legitimation wurde dabei auf verschiedenen lokalen Ebenen nochmals neu geregelt, wobei sowohl Sakralisierungen wie Entsakralisierungen der politischen Ordnungen auftraten ${ }^{82}$.

${ }^{79}$ Vgl. hier neben den Klassikern wie MARC BLOCH, Les rois thaumaturges. Étude sur le caractère surnaturel attribué à la puissance royale, particulièrement en France et en Angleterre, Strasbourg Paris 1924, zum Mittelalter nur JOACHIM EHLERS (Hg.), Die französischen Könige des Mittelalters: Von Odo bis Karl VIII. 888-1498, München 1996.

${ }^{80}$ Vgl. etwa William E. LunT, Financial Relations of the Papacy with England, 2 Bde., Cambridge 1962; methodisch differenziert zum Zugriff auf herrschaftliche, wirtschaftliche und religiöse Motivationen politischen Handelns KARL UBL, Philipp IV. und die Vernichtung des Templerordens. Eine Neubewertung, in: Francia 39, 2012, S. 69-88.

${ }^{81}$ Vor allem der Albigenserkrieg und die Auseinandersetzungen im Italien des 13. Jahrhunderts könnten als Beispiele genannt werden. Zu den jeweils äußerst komplexen historischen Abläufen vgl. JÖRG OBERSTE, Der 'Kreuzzug' gegen die Albigenser. Ketzerei und Machtpolitik im Mittelalter, Darmstadt 2003; zu Italien mit weiteren Verweisen CHRISTOPH F. WEBER, Zeichen der Ordnung und des Aufruhrs. Heraldische Symbolik in italienischen Stadtkommunen des Mittelalters (Symbolische Kommunikation in der Vormoderne) Köln u. a. 2011, S. 130, S. 188 f. und S. 376 f.; DONALD PRUDLO, The Martyred Inquisitor: The Life and Cult of Peter of Verona (Church, Faith, and Culture in the Medieval West) Aldershot 2008.

82 Vgl. mit Verweisen MatThias POHLIG, Religionsfrieden als pax politica. Zum Verhältnis von Religion und Politik im konfessionellen Zeitalter, in: GABRIEL - GÄRTNER - POLLACK (Hgg.), Umstrittene Säkularisierung (wie Anm. 4) S. 225-251; MATTHias Pohlig u. a. (Hgg.), 
An die Stelle der graduellen Trennung von Religion und Politik könnte man bei Einbezug dieser regionalen Verschiedenheiten eine dynamischere historische Erzählung setzen: Das Verhältnis von geistlicher und weltlicher Gewalt wurde in verschiedenen europäischen Regionen wiederholt neu verhandelt - teils durchaus mehrmals. Konzeptuell ähnliche Unterscheidungen von geistlich und weltlich wurden dabei immer wieder aufgegriffen und in wechselnden politischen Konstellationen durchgespielt. Ein eigentlicher 'Beginn' einer Scheidung von geistlich und weltlich scheint daher schwer zu bestimmen. Für den Investiturstreit spricht zwar die Forschungsgeschichte. Doch beruht sie ja auf dem alten Zerfallsparadigma. Die Fokussierung auf Frankreich und England würde dagegen - je nachdem welche Ereignisse man aus der historischen Vogelperspektive hervorhebt - einen früheren oder viel späteren Umschlagpunkt bewirken. Ansprüche auf Überordnung der geistlichen Gewalt kann man ja mit Althoff in die Krisen der Karolingerzeit datieren, wo sie nicht vom Papst, sondern von den fränkischen Bischöfen vertreten wurden. Oder man kann traditionelle Marksteine der anglophonen und frankophonen Forschung bevorzugen und den Konflikt zwischen Philipp IV. und Bonifaz VIII. an der Wende zum 14. Jahrhundert oder gar die Lossagung des englischen Königs von der Papstkirche im 16. Jahrhundert als entscheidende Wende zur Verselbständigung des Staates von kirchlicher Aufsicht ansehen. Die Vielfalt der möglichen Zäsuren, die man leicht erweitern könnte, verstärkt freilich nur den Eindruck, dass wir es mit einer Geschichte wiederholter Neuverhandlungen ähnlicher Themen über das gesamte Mittelalter (und Teile der Antike wie der Neuzeit) zu tun haben.

Um die Linearität der bisherigen historischen Erzählungen, die großenteils dem älteren Zerfalls- oder Freisetzungsparadigma angehören, noch deutlicher zu problematisieren, könnte man zudem auf Sakralisierungen politischer Herrschaft hinweisen. Sie wechseln sich mit den in der älteren Forschung fokussierten Entsakralisierungen ab und scheinen sie oftmals sogar zu bedingen. Das Narrativ einer Trennung von geistlich und weltlich funktioniert etwa nur, wenn man auf das 11. bis 15. Jahrhundert fokussiert. Fragt man nach dem 4. bis 18. Jahrhundert, sieht es anders aus ${ }^{83}$. In Spätantike und Frühmittelalter werden, wie wir wissen, Vorstellungen religiös legitimierter Herrschaft eifrig ausgebaut, im 8. und 9. Jahrhundert etwa von den karolingischen Herrschern. Mit Unregelmäßigkeiten wie einem König Heinrich I., der das Angebot der Salbung ausschlug, setzen sich Sakralisierungsprozesse vom fränkischen Karolingerreich zu den Ottonen und Saliern bis zu Heinrich IV. und darüber hinaus weiter fort und zeigen verschiedene Ausformungen. Unter dem Druck

Säkularisierungen in der Frühen Neuzeit. Methodische Probleme und empirische Fallstudien (Zeitschrift für Historische Forschungen, Beihefte 41) Berlin 2008.

83 Vgl. zum Folgenden FrANZ-REINER ERKENS, Herrschersakralität im Mittelalter: von den Anfängen bis zum Investiturstreit, Stuttgart 2006; zu anderen Formen transzendenter Legitimation von Herrschern s. CRISTINA ANDENNA - GERT MELVILLE, Dynastie, Idoneität und Transzendenz. Vergleichende Untersuchungen zum hohen und späten Mittelalter, in: HANS VORLÄNDER (Hg.), Transzendenz und Gemeinsinn. Themen und Perspektiven des Dresdner Sonderforschungsbereichs 804, Dresden ${ }^{2} 2011$, S. 40-45. 
des Papsttums, aber auch auf der Basis rein weltlicher Konflikte, wurden zwischen 11. und 14. Jahrhundert zwar oft auch profane Legitimationen des Königtums betont. Gleichzeitig holten aber die west- und nordeuropäischen Herrscher eine sakrale Überhöhung ihrer Herrschaft nach - oder brachten die Sakralität ihrer Königsherrschaft gegen den Papst ins Spiel, wie im Falle der französischen Monarchie unter Philipp IV., die den Papst auch mit religiöser Propaganda angriff und Frankreich als Land des erwählten Volkes, den französischen Herrscher als eigentliche Säule der Kirche und „allerchristlichsten König“ darstellen lie $\beta^{84}$. Spätestens mit der Reformation und Konfessionalisierung steigt ein vergleichbarer Bezug diverser Herrscher und Obrigkeiten auf religiöse Legitimationsgründe wiederum sprunghaft an, während er mit der Aufklärung eher zurückgeht beziehungsweise sich pluralisiert und transformiert. Dabei werden jeweils ganz unterschiedliche Mechanismen der Verknüpfung von religiöser Herrscherlegitimation und Religionspolitik wirksam, die hier nur gestreift werden können. Die Schübe der Sakralisierung der päpstlichen Zentralgewalt, so wird aber deutlich, stehen teilweise mit vorausgehenden oder antwortenden Schüben der Sakralisierung lokaler weltlicher Herrschaft in Wechselwirkung ${ }^{85}$.

Aber inwiefern, so könnte man nun fragen, ist es problematisch, solche Entwicklungen zusammenzufassen? Ist das Ergebnis - eine graduelle Trennung der geistlichen und weltlichen Begründung politischer Macht - nicht am Ende doch dasselbe? Das mag der Fall sein, doch geben sich ja weder historische noch soziologische Untersuchungen damit zufrieden. Es geht vielmehr um das 'Wie' solcher Entwicklungen, um die Faktoren, die auf historische wie gegenwärtige Vorgänge einwirken. Da im Moment die Revision verschiedener älterer Großerzählungen in globalgeschichtlich vergleichender Forschung ansteht, geht es zudem durchaus auch um das 'Wann' und 'Wo'. Wenn man sich zu stark auf die ältere Erzählung einer graduellen Differenzierung verschiedener gesellschaftlicher Funktionsbereiche in Europa seit dem Hochmittelalter einlässt, drohen auf diesen Ebenen Fehleinschätzungen.

Wie mir scheint, müsste man daher anstelle der Trennung der Bereiche Religion und Politik konsequent ihre Verknüpfung thematisieren. Das Beispiel der Auseinandersetzungen von Kaisern und Päpsten rückt zwar etwa konkrete historische Kontexte in den Vordergrund und vollzieht auf Akteursebene nach, dass tatsächlich Interessengegensätze bestanden, die zu neuen Abgrenzungen von geistlicher und weltlicher Herrschaft führten. Doch droht regionale Machtpolitik einseitig wahrgenommen zu werden, und es könnte die Vorstellung aufkommen, dass Staaten und ihre Vorläufer eigentlich immer schon von einer geistlichen Oberherrschaft

${ }^{84}$ Vgl. hier nur STRAYER, France: The Holy Land (wie Anm. 78) S. 305-307.

85 Vgl. zum Begriff der Sakralisierung beziehungsweise 'immanenten Sakralisierung' mit Verweisen VOLKHARD KRECH, Dynamics in the History of Religion. Preliminary Considerations on Aspects of a Research Programme, in: KRECH - STEINICKE (Hgg.), Dynamics in the History of Religion (wie Anm. 9) S. 15-70, hier S. 25-27. 
unabhängig sein wollten, und eine graduelle Differenzierung daher unausweichlich war. Wenn man stattdessen nochmals nach der Machtgrundlage des aufstrebenden Reformpapsttums fragt, wird nicht nur deutlich, dass es von genuinen religiösen Impulsen gestützt und von den römisch-deutschen Herrschern intensiv gefördert worden war. Es gab auch mehrere andere regionale Akteure des 11. Jahrhunderts, die eine gesteigerte Stellung des Papsttums förderten. Maureen I. Miller hat jüngst darauf hingewiesen, dass es im Vorlauf des Investiturstreits zu neuen Bündnissen gekommen war, da in Italien sowie in Westeuropa eine Reihe neuer, legitimationsbedürftiger Herrschaftsverbände entstanden war. Sie bezogen vom Papsttum Legitimität, wurden aber im Gegenzug auf die reformerische religiöse Agenda festgelegt ${ }^{86}$. Vielfach unterstützten politische Akteure des Mittelalters also die Rolle des Papsttums als Spitze der europäischen Christenheit, teils vielleicht aus Kalkül, teils aber auch aus religiöser Überzeugung. $\mathrm{Ob}$ zwischen geistlicher und weltlicher Gewalt Interessengegensätze oder Interessenkongruenz bestehen, ist dabei historisch kontingent.

In zweiter Linie neigen die älteren, um die graduelle Trennung von geistlicher und weltlicher Gewalt organisierten historischen Erzählungen dazu, interne Entwicklungen dieser Bereiche zu unterschlagen, die historisch eine große Rolle spielen. Doch auch die Verknüpfung mit weiteren Entwicklungen, etwa denen zwischen Recht, Religion und Politik kommt zu kurz. Detlef Pollack stellt zu Recht heraus, dass der Bezug auf das Recht eine wichtige Ressource in der Selbstbehauptung der weltlichen Herrscher war. Er diskutiert, wie oben erwähnt, dass er von den deutschen Herrschern teils gegen die Machtansprüche des Papsttums in Stellung gebracht wurde. Dazu wird die Überlegung Dilchers herangezogen, dass das Recht durch Aufladung mit sakralen Elementen geradezu sakralisiert wird ${ }^{87}$. Doch droht diese Entwicklung unterbetont zu werden, wo sie zu stark in ein Narrativ von der Trennung von geistlicher und weltlicher Gewalt einbezogen wird. Die Rechtsentwicklung war ja keineswegs nur Resultat von Konflikten zwischen Papsttum und weltlichen Gewalten. Neuere Forschungen zur Entstehung politischer Ordnungen weisen im Gegenteil darauf hin, dass politische Konflikte im Innern mittelalterlicher Herrschaftskomplexe ein wesentliches Movens der institutionellen Binnendifferenzierung und Verrechtlichung waren. Thomas N. Bisson hat erst 2009 die Entstehung von Konzepten politischer Verantwortlichkeit im Hochmittelalter in einer umfassenden Studie als Resultat langwieriger lokaler Kleinkonflikte dargestellt. Sie ergaben sich in der hochmittelalterlichen Phase politischer und wirtschaftlicher Verdichtung und eifrigen Landesausbaus (also auf der Basis unterliegender ökonomischer und sozialer Faktoren) zwischen Herren und Untergebenen in großer

86 Vgl. Maureen C. Miller, Italy in the Long Twelfth Century: Ecclesiastical Reform and the Legitimization of a New Political Order, 1059-1183, in: NOBLE - VAN ENGEN (Hgg.), European Transformations (wie Anm. 62) S. 117-131.

${ }^{87}$ Vgl. wie oben PolLACK, Die Genese (wie Anm. 4) bei Anm. 107-108. 
Zahl und bewirkten seiner Ansicht nach schließlich einen Lernprozess ${ }^{88}$. Jüngere Forschungen haben zudem die tiefergehenden historischen Wurzeln solcher Verrechtlichungsprozesse aufgezeigt, indem sie auf ungeschriebene „Spielregeln“ und informelle Mechanismen der Konfliktlösung wie die Vermittlung hingewiesen haben, die wichtige Vorläuferentwicklungen für Bürokratisierungsprozesse boten ${ }^{89}$. Auch ist wiederum klar geworden, dass Prozesse institutioneller Verdichtung regional unterschiedlich ausfallen konnten: Wie Theo Broekmann zeigt, gab es beispielsweise im Königreich Sizilien heftige Widerstände gegen die straffe, modernisierende Organisation der Monarchie durch Roger II., denn den Zeitgenossen, insbesondere dem Adel, erschien diese neue Ordnung als Tyrannei. Ähnlich wie im Reich bevorzugten sie andere, ebenfalls funktionsfähige politische Mechanismen, die lediglich aus moderner Perspektive weniger fortschrittlich erscheinen ${ }^{90}$. Die zunehmende Verdichtung weltlicher (wie geistlicher) Herrschaft wird also wiederum auch von bestimmten Prozessen des regionalen Zusammenwachsens angetrieben und von spezifischen Akteurskonstellationen gesteuert, für die in einer Erzählung zur Trennung von geistlich und weltlich kein Platz ist.

Auch in einem dritten und letzten Bereich ergeben sich mögliche Alternativen, wenn man die Überlegungen Pollacks zur Trennung von Religion und Politik modifizierend weiterverfolgt. Im Bereich der Herrscherlegitimation, den er zu Recht als Bereich direkter gegenseitiger Abgrenzung beziehungsweise Annäherung von geistlicher und weltlicher Gewalt hervorhebt, könnte man etwa nicht nur eine Trennung, sondern vor allem eine Pluralisierung als historischen Wirkungszusammenhang ansehen. Es erscheint tatsächlich äußerst signifikant für die Stellung und das Selbstverständnis weltlicher Herrschaft, wenn Könige und Kaiser wie Friedrich I. Barbarossa neue Begründungen ihrer Herrschaft beibrachten. Wie Pollack hervorhebt, griff man in Konflikten zwischen Kaiser und Papst zum Beispiel im 12. Jahrhundert auf rechtliche und historische Begründungen für die Ansprüche des Kaisertums zurück, diversifizierte also die Legitimationsgründe, die den Bereich des Politischen stützten ${ }^{91}$. Zudem wurden jedoch auch in der religiösen Legitimation

${ }^{88}$ Vgl. Thomas N. Bisson, The Crisis of the Twelfth Century: Power, Lordship, and the Origins of European Government, Princeton (NJ) 2009.

${ }^{89}$ Vgl. Gerd AlthofF, Spielregeln der Politik im Mittelalter. Kommunikation in Frieden und Fehde, Darmstadt 1997; HERMANN KAMP, Friedensstifter und Vermittler im Mittelalter (Symbolische Kommunikation in der Vormoderne) Darmstadt 2001; KOZIOL, Begging Pardon (wie Anm. 66). Zum Übergang zwischen Schriftlichkeit und Mündlichkeit, informellen und formellen politischen Mechanismen vgl. auch PETRA SCHULTE, Scripturae publicae creditur. Das Vertrauen in Notariatsurkunden im kommunalen Italien des 12. und 13. Jahrhunderts (Bibliothek des Deutschen Historischen Instituts in Rom 101) Tübingen 2003; CHRISTOPH DARTMANN, Politische Interaktion in der italienischen Stadtkommune (11.-14. Jahrhundert) (Mittelalter-Forschungen 36) Ostfildern 2012.

${ }^{90} \mathrm{Vgl}$. THEO BROEKMANN, 'Rigor Iustitiae': Herrschaft, Recht und Terror im normannisch-staufischen Süden (1050-1250) (Symbolische Kommunikation in der Vormoderne) Darmstadt 2005.

91 Man könnte noch auf Veränderungen im Bereich der wissenschaftlich-gelehrten Qualifikation von Herrschern hinweisen, vgl. zuletzt KARL UBL, Der Gelehrte bei Marsilius von Padua und Wilhelm von 
mittelalterlicher Herrscher Alternativen formuliert: Die deutschen Könige führten gegen die Vorstellung einer päpstlichen Beauftragung zur Herrschaft eigene Begründungen für ihr Amt an, etwa die von Heinrich IV. wie von Friedrich I. und anderen geäußerte Vorstellung, dass die königliche Herrschaft gottgewollt sei ${ }^{92}$. Pollack nennt dieses Argument einer Gottunmittelbarkeit des Herrschers „metaphysisch“, doch ist es, funktional bestimmt, durchaus religiös. Religion wird nach dieser Sichtweise also nicht aus dem Bereich der Politik zurückgedrängt, sondern mit einer anderen, konkurrierenden Form religiöser Begründung ersetzt. Ein Teilbereich des Religiösen erfährt eine interne Pluralisierung. Wo politische Prätendenten jedoch mehrere Formen religiöser Legitimation zur Auswahl haben, muss die Verknüpfung von Religion und Politik lockerer werden. Diese Diversifizierung scheint der wesentliche Auslöser einer veränderten Form der Differenzierung von Religion und Politik zu sein.

Ihre Fortsetzungen kann man bis in die Gegenwart verfolgen, in der hierzulande religiöse und weltanschauliche Pluralität die Grundlage einschlägiger Legitimationsmechanismen geworden ist. Doch auch heute sind nicht Religion und Politik, sondern lediglich Staat und Kirche getrennt. Nicht nur gibt es weiterhin beispielsweise Parteien mit religiösen Wertbezügen. Politik wird auch in stark säkularisierten Kulturen typischerweise nicht im Sinne bloßer Machtpolitik legitimiert. Es ist etwa nicht die Rede davon, dass im deutschen Bundestag ganz ausdrücklich das Gesetz des Stärkeren regiert. Im Gegenteil wird gerade die Auswahl von Amtsträgern weiterhin durch Gesichtspunkte ihrer religiösen oder aber moralischen Qualifikation mit gesteuert. Ihr Handeln, das sich ansonsten nach Logiken der Politik organisieren mag, muss zumindest in der rechtfertigenden Darstellung nach außen irgendwie auf Werte bezogen werden. Die Moral oder persönliche Integrität, die ein politischer Amtsträger vorweist, kann aber mittlerweile dank des Konzepts der Religionsfreiheit und einer Vielfalt von profanen Moralvorstellungen aus jeder beliebigen Religion oder aus einer areligiösen Weltanschauung abgeleitet sein - der Bereich hat sich intern enorm diversifiziert, und die Verknüpfung der Politik mit religiösen Legitimationen ist teils von Bindungen an Bereiche wie Recht und Wissenschaft abgelöst worden. Dieser Prozess scheint mir wesentlich von Diversifizierungen ermöglicht worden zu sein. In historischen Situationen, in denen religiös oder weltanschaulich unterschiedlich orientierte Gruppen zu einem Konsens finden mussten, einigten sie sich dann typischerweise darauf, diese Orientierungen aus dem Bereich des Politischen auszuklammern ${ }^{93}$.

Ockham. Zur Abgrenzung von politischer und gelehrter Autorität in der Philosophie des 14. Jahrhunderts, in: Das Mittelalter 17, 2012, S. 16-33.

92 Vgl. zu Heinrich IV. FranZ-REINER ERKENS, Der pia Dei ordinatione rex und die Krise sakral legitimierter Königsherrschaft in spätsalisch-frühstaufischer Zeit, in: JARNUT - WEMHOFF (Hgg.), Vom Umbruch zur Erneuerung (wie Anm. 23) S. 71-101; zu Friedrich I. die Verweise bei PoLLACK, Die Genese (wie Anm. 4) bei Anm. 103.

${ }^{93}$ Ich möchte also Säkularisierung durch Verdrängung des Religiösen aus dem politischen Raum stärker betonen (vgl. etwa CHARLES TAYLOR, A Secular Age, Cambridge [MA] 2007, S. 1-2); vgl. Belege etwa 
Man könnte also das den älteren Erzählungen zugrundeliegende Kausalverhältnis umdrehen: Die Trennung zwischen den Bereichen des Religiösen und des Politischen ist (zumal im Mittelalter) nicht das Resultat einer zunehmenden Trennung von geistlicher und weltlicher Gewalt oder von Staat und Kirche. Im Gegenteil gab es verschiedene Formen der konzeptuellen Trennung zwischen Religion und Politik eigentlich durchgehend. Wo aber mehrere konkurrierende religiöse oder politische Akteure in Konflikt gerieten, wurden zur Vermeidung ständiger Konflikte zumeist Ordungskonzepte für diese Bereiche durchgesetzt, also 'Staaten' beziehungsweise politische Ordnungen und 'Kirchen' etabliert oder verändert. Wo innerhalb von 'Staaten' und 'Kirchen' weiterhin religiöse Konflikte bestanden, wurden räumliche und sachliche Ordnungsmuster gefunden, um die Praxis des Zusammenlebens von Konflikten halbwegs freizuhalten. Teils erreichte man religiösen oder politischen Konsens schlicht auf dem Weg der Gewalt. Wo die Machtverhältnisse dagegen nicht ausreichten, um Vereindeutigungen herbeizuführen, arrangierte man sich typischerweise mit Formen religiöser Diversität ${ }^{94}$.

Um das Verhältnis von Religion und Politik in einer der Gegenwartsforschung angemessenen Weise zu beschreiben, scheint es daher nur eine Lösung, die Trennung von geistlicher und weltlicher Gewalt zu verfolgen. Als anderen Ansatzpunkt kann man daneben verfolgen, wo historisch gesehen die regionalen, sozioökonomischen und kulturellen Verdichtungspunkte liegen, die einen veränderten Umgang mit religiöser Diversität ermöglichten. Diese Frage müsste aus historischer Perspektive wohl zunächst in diejenige nach regionalen Verdichtungsprozessen umgesetzt werden, in denen verschiedene religiöse und politische Überzeugungen überhaupt zueinander in Beziehung traten. Dann könnte man fragen, welche inneren Dynamiken des Religiösen, Politischen etc. und welche Verknüpfungen zwischen Religion, Politik, Recht und anderen Bereichen in spezifischen Akteurskonstellationen auftraten.

Tatsächlich werden derartige Fragen in der Mittelalterforschung derzeit vielfach gestellt. Das Thema der inter- und transkulturellen Verflechtungsgeschichte boomt, nicht nur in der Mittelalter-, sondern auch in der Neuzeitgeschichte ${ }^{95}$. Für den Bereich der Mittelaltergeschichte bildet in letzter Zeit vor allem die kommunikative und sozioökonomische Verdichtung und transkulturelle Verflechtung rund um das Mittelmeer

bei Pohlig, Religionsfrieden (wie Anm. 82); Alexandra Walsham, Zu Tisch mit Satansjüngern. Geistliche und weltliche Soziabilität im nachreformatorischen England, in: ANDREAS PIETSCH Barbara StOlLberG-RILINGER (Hgg.), Konfessionelle Ambiguität. Uneindeutigkeit und Verstellung als religiöse Praxis in der Frühen Neuzeit (Schriften des Vereins für Religionsgeschichte 214) Göttingen 2013, S. 285-313.

$94 \mathrm{Vgl}$. methodisch anregend JENNY RAHEL OESTERLE, Grenzenlose Multireligiosität? Rivalitäten um Herrschergunst und Ämtervergabe am Kalifenhof von Kairo im 10. Jahrhundert, in: BORGOLTE Tischler (Hgg.), Transkulturelle Verflechtungen (wie Anm. 10) S. 195-206; forschungskritisch Kenneth BaXter Wolf, Convivencia in Medieval Spain: A Brief History of an Idea, in: Religion Compass 3, 2009, S. 72-85; zur Frühen Neuzeit PIETSCH - STOLLberg-Rilinger (Hgg.), Konfessionelle Ambiguität (wie Anm. 93); AlEXANDra Walsham, Charitable Hatred. Tolerance and Intolerance in England, 1500-1700, Manchester 2006.

${ }^{55}$ Vgl. die Literatur oben bei Anm. 10, 16, 17. 
einen wichtigen Schwerpunkt, da sie den Blick der älteren, auf Westeuropa konzentrierten Forschungen ergänzen kann ${ }^{96}$. Die innere Dynamik des Religiösen ist, wie einleitend erwähnt, ebenfalls ein aktuelles Thema ${ }^{97}$.

Als weitere wichtige Form des Zugriffs auf religiöse Dynamiken des Mittelalters haben sich daneben Forschungen entwickelt, die Schnittstellen zwischen Religion und anderen Bereichen thematisieren. Dabei sind mittlerweile auch Prozesse der Verknüpfung von Religion mit Recht oder Politik ins Blickfeld geraten: Wie Gerd Althoff jüngst gezeigt hat, wurden etwa neue biblische Begründungen für die legitime Anwendung von Gewalt gefunden und schließlich in das kanonische Recht eingeschrieben, als das Reformpapsttum im späteren 11. Jahrhundert politische und militärische Initiativen gegen Gegner und Dissidenten zu legitimieren suchte ${ }^{98}$. Wie Christine Caldwell Ames zeigt, wurde auch die Verfolgung von Häretikern durch die hochmittelalterliche Inquisition durch eine religiöse Aufwertung von gewaltsamer Verfolgung ermöglicht - und ist nicht allein Resultat der Entstehung 'modernerer' Verfolgungsstrukturen, wie Robert I. Moore vorschlug 99 .

\section{HISTORISCHE RAHMENANNAHMEN UND VERLAUFSPROZESSE: BOURDIEU VERSUS LUHMANN}

Doch wie können wir solche Prozesse - also die innere Pluralisierung des religiösen Bereichs und seine Verknüpfung mit anderen gesellschaftlichen Sphären theoretisch rahmen? Detlef Pollack schlägt eine Adaptation der Luhmannschen Systemtheorie vor. Eine für die mediävistische Forschung wohlvertraute und für die geschilderten Anliegen näherliegende theoretische Ressource wäre aber auch in der Feldtheorie Pierre Bourdieus vorhanden. Sie scheint mir gegenüber den Ansätzen der Systemtheorie einfacher zu dynamisieren zu sein.

Ähnlich wie die Systemtheorie Luhmanns folgt die Feldtheorie nicht dem älteren Dekompositions-, sondern einem Emergenzparadigma, geht also nicht von einem gesellschaftlichen Zerfall aus, sondern von der Entstehung übergeordneter gesellschaftlicher Strukturen ${ }^{100}$. Wo verschiedene Akteure ähnliche soziale Praktiken

96 Vgl. diverse Literatur oben bei Anm. 10, mit einer Problematisierung des typischerweise auf das Christentum orientierten Blicks auch PHILIPPE BÜTTGEN u. a. (Hgg.), Les Grecs, les Arabes et nous. Enquête sur l'islamophobie savante, Paris 2009.

${ }_{97} \mathrm{Vgl}$. die Literatur oben bei Anm. 11.

98 Vgl. GERD AlthOFF, „Selig sind, die Verfolgung ausüben“. Das Papsttum und die Gewalt im Hochmittelalter, Darmstadt 2013; vergleichbare Argumentationen etwa auch von ROBERT I. MOORE, The War on Heresy, Cambridge (MA) 2012.

${ }_{99}$ Vgl. Christine CALDwell AmeS, Inquisition (wie Anm. 11); vgl. auch DiES., Righteous Persecution: Inquisition, Dominicans, and Christianity in the Middle Ages, Philadelphia 2009; ROBERT I. MOORE, The Formation of a Persecuting Society. Authority and Deviance in Western Society, 950-1250, Malden (MA) 22007.

100 Vgl. zum Konzept der Emergenz bei Luhmann knapp KNEER, Differenzierung (wie Anm. 30) S. 140 143; anschaulich auch RAINER WALZ, Theorien sozialer Evolution und Geschichte, in: FRANK BECKER (Hg.), Geschichte und Systemtheorie (wie Anm. 6) S. 29-75, S. 46-47. 
vollziehen und dabei miteinander in Konkurrenz geraten, entstehen nach Bourdieus Sicht soziale 'Felder'. Sie gewinnen Autonomie, indem sie sich eigenständig nach inneren Kriterien abgrenzen und (zumeist unausgesprochene, habitualisierte) Regeln und Logiken ausbilden. Sie sind somit in etwa analog zu Konzepten von Wertsphären oder Funktionssystemen zu denken.

Bourdieus Verständnis der Logik sozialer Felder erlaubt, Dynamiken der regionalen Verdichtung einzubeziehen, und gerade zum religiösen Feld hat er sich mehrfach geäußert. Wo mehrere religiöse Akteure miteinander in Kontakt geraten, so die räumliche Metapher des Feldes, müssen sie sich zueinander positionieren. Gemäß der inneren Dynamik sozialer Felder werden dann auch die Grenzen des Feldes neu bestimmt: Da Bourdieu die Felder immer vom Zentrum her definiert sieht, kann eine Neuabgrenzung des gesamten Feldes erwartet werden, wo neue Akteure innerhalb eines Feldes die Oberhand gewinnen ${ }^{101}$. Das ist hilfreich, wenn man die historisch wandelbare Gestalt von Phänomenen im Auge behalten will, die wir heute als Recht, Religion oder Politik zusammenfassen. Sie konnten historisch sozusagen ständig mit neuen Varianten überschrieben werden, so dass sich nach wiederholten Neubestimmungen der Felder sozusagen eine Archäologie mit verschiedenen Schichten kultureller Formationen darbietet, die wir historisch als Recht, Religion etc. bestimmen.

Die intensive religiöse Erneuerung des hochmittelalterlichen lateinischen Christentums bei gleichzeitiger Ausweitung der Wahrnehmungshorizonte über die christianitas hinaus erscheint in diesem Modell etwa als Verdichtung des religiösen Feldes. Der päpstlich geführten Kirche gelang es, eine dominante Stellung innerhalb des europäischen regionalen Feldes zu erringen. Sie grenzte sich dann vehement gegen ältere Vorstellungen ab, nach denen ein weltlicher Herrscher wie Karl der Große als Lenker und rector der Kirche auftreten konnte, oder einzelne Bischöfe unabhängig vom Papsttum agieren durften. Die religiöse Zugehörigkeit wurde dabei mit rechtlichen Bindungen verknüpft, indem man den rechtlichen Ungehorsam gegen den Papst nun als religiöse Verfehlung der Häresie definierte und so ins religiöse Feld einschloss. Zur christlichen Religion zu gehören, hatte nun eine spezifischere Bedeutung. Später wurde die rechtliche Komponente des Religionskonzepts von anderen religiösen Akteuren negiert und wiederum überschrieben.

Bourdieu sieht insgesamt die Möglichkeit vor, dass ein Feld an Autonomie gewinnt oder verliert. Das erlaubt, die oben diskutierten Prozesse religiöser und politischer Pluralisierung und Diversifizierung als veränderliche Verschränkung verschiedener Felder zu denken. Paradigmatisch hat schon Bourdieu selbst eine Auflösung des 'religiösen Feldes' durchexerziert102: Wie er argumentiert, wurde es im 20. Jahrhundert an seinen Rändern sozusagen porös und erfuhr eine Diversifizierung. Dabei erfolgten nicht nur neue innere Differenzierungen, sondern es wurden auch

101 Vgl. besonders die Operationalisierung von REUTER, Grenzarbeiten (wie Anm. 15).

102 Vgl. PIERre Bourdieu, Die Auflösung des Religiösen, in: DERS., Rede und Antwort, Frankfurt a. M. 1992, S. 231-237. 
Elemente der seit Jahrhunderten benachbarten Felder der Medizin und Wissenschaft in Gemengelagen wie Esoterik, Psychotherapie, Astrologie etc. ins religiöse Feld eingeschlossen.

Derartige Überlegungen hat in letzter Zeit die Religionswissenschaftlerin Astrid Reuter zu einer Frage nach wiederholten „Grenzarbeiten am religiösen Feld“ weiterentwickelt. Sie schlägt vor, Akteure in den Blick zu nehmen, die bestimmte Phänomene in das religiöse Feld ein- oder ausschlossen, indem sie diese als religiös auswiesen oder ihre Zugehörigkeit zur Religion bestritten ${ }^{103}$. Der oben diskutierte Verweis mittelalterlicher Herrscher auf die Gottunmittelbarkeit ihrer Herrschaft kann etwa als Praxis verstanden werden, mit dem diese Herrscher ihren Status in einer Situation der Krise als religiös auswiesen und so gegen Angriffe und Veränderungen $\mathrm{zu}$ schützen versuchten. Im kanonischen Recht des 13. Jahrhunderts suchte man dagegen zum Bespiel bestimmte Formen der kirchlichen Rechtssetzung aus dem Bereich des Religiösen herauszunehmen, um sie dynamisieren zu können: Das zunehmend gestaltungsfreudige Papsttum wollte nun bestimmte Entscheidungen nicht mehr als sakral legitimiert und überzeitlich gültig ausweisen, sondern gerade als situativ veränderlich. Bestimmte Fälle von Rechtsentscheidungen wurden daher nun juristisch als rein innerweltliche, veränderliche Entscheidungen definiert, die der Papst sozusagen aus bloß menschlichem Ermessen traf. Andere Teile der kirchlichen Ordnung wies man dagegen als göttlich gewollt und unveränderlich aus (wiewohl heftig umstritten sein konnte, welche das waren) ${ }^{104}$. Vergleichbare Grenzarbeiten kann man auch an diversen weiteren Stellen annehmen.

Wie jüngst vorgeschlagen wurde, kann man Bourdieus Feldtheorie daher zu einem historischen Rahmen erweitern, innerhalb dessen verschiedene Grenzarbeiten und innere Diversifizierungen von der Antike bis in die Gegenwart untersucht werden können. Zwar hat Bourdieu selbst keine weitergehenden historischen Verlaufsannahmen vorgeschlagen. Doch gerade diese Offenheit erscheint für das historische Arbeiten derzeit als Chance: Der übergreifende Rahmen lässt genügend Raum für die aktuell laufenden Untersuchungen kurz- und mittelfristiger Wandlungsprozesse und für transkulturelle Vergleiche.

Mit jüngeren Forschungen könnte man aber in etwa annehmen, dass die wichtigsten sozialen Felder, insbesondere mehrere regionale religiöse Felder, bereits seit der Antike vorhanden waren, sich dann kontinuierlich verlagerten, an Autonomie

\footnotetext{
103 Vgl. REUTER, Grenzarbeiten (wie Anm 15); REUTER, Charting the Boundaries (wie Anm. 15). Reuter adaptiert die Bourdieusche Feldtheorie insbesondere durch Dynamisierung, unter Heranziehung von Ansätzen wie THOMAS F. GIERYN, Boundary-work and the Demarcation of Science from NonScience: Strains and Interests in Professional Ideologies of Scientists, in: American sociological review 48/6, 1983, S. 781-795.

104 Vgl. Brian TIERneY, Origins of Papal Infallibility 1150-1350. A Study on the Concepts of Infallibility, Sovereignty and Tradition in the Middle Ages (Studies in the History of Christian Thought 6) Leiden 1972, besonders S. 45-58.
} 
gewannen oder verloren und sich miteinander verflochten ${ }^{105}$. Schon mit der Antike müsste man dann ein religiöses Feld rund um das Mittelmeer postulieren, das mit anderen regionalen Feldern in Kontakt geriet. Im Anschluss daran könnte man phasenweise regionale Entflechtung im Frühmittelalter ansetzen, der ab dem Hochmittelalter eine erneute Phase überregionaler Verflechtung folgt. Sie erschiene als Entstehung eines neuen, nunmehr Europa und den Mittelmeerraum übergreifenden religiösen Feldes. Seit dem Spätmittelalter bis ins späte 18. Jahrhundert schließen sich dann mit zunehmender globaler Verflechtung Schübe regionaler Neuausrichtungen dieses religiösen Feldes an. Die Neuverhandlung religiöser Werte und Traditionen in der Gegenwart ließe sich dann schließlich, wie etwa auch Karl Gabriel argumentiert, als Teil der Entstehung eines neuen globalen Bezugssystems der Religion deuten ${ }^{106}$.

Für das Mittelalter kann man auf dieser Basis auch weitere Überlegungen anstellen: Im Verlauf der regionalen Entflechtung des Frühmittelalters dürften die antiken Felder der Wissenschaft und des Rechts an Autonomie verloren haben, da Inhalte der Wissenschaft ins religiöse und Inhalte des Rechts ins politische Feld eingeschlossen wurden. Im Verlauf des Hochmittelalters gewannen diese Felder jedoch wieder an Autonomie und entwickelten neue, mit der Antike nicht mehr identische Konturen. Dabei spielten einerseits zugrundeliegende Strukturänderungen eine Rolle, vor allem Prozesse politischer und ökonomischer Verdichtung und Arbeitsteilung ${ }^{107}$. Andererseits ergaben sich schubweise Veränderungen durch regionale Verflechtungen und die Intensivierung lokaler und überregionaler Kommunikation durch Mediengebrauch und Technik. Es kam im Zuge der wirtschaftlichen und politischen Vernetzung in Europa sowie im Mittelmeerraum an bestimmten kulturellen Knotenpunkten generell mehrfach zu innereuropäischen und darüber hinausgreifenden Schüben der Entwicklung. Dabei entstanden gemeinsame Symbolhaushalte und Diskurse, von einer gemeinsamen diplomatischen Sprache bis zur transkulturellen aristotelischen Philosophie ${ }^{108}$.

Ein solches, an Bourdieus Feldtheorie angelehntes historisches Modell ist im Moment freilich nicht umfassend historisch ausgearbeitet und muss als experimentell ausgewiesen werden. Wo große historische Zäsuren liegen, und welche historische Erzählung wir ihnen unterlegen wollen - etwa eine Erzählung zunehmender

105 Vgl. den Band KreCH - Steinicke (Hgg.), Dynamics in the History of Religion (wie Anm. 9), besonders den Beitrag KRECH, Dynamics in the History of Religion (wie Anm. 85) hier S. 48-69; PETER BEYER, Religions in Global Society, London - New York 2006.

106 Vgl. KARL GABRIEL, Säkularisierung und Wiederkehr der Religionen unter den Bedingungen der Globalisierung, in: ANSGAR KREUTZER - FrAnZ GruBER (Hgg.), Im Dialog. Systematische Theologie und Religionssoziologie (Quaestiones disputatae 258) Freiburg u. a. 2013, S. 267-277.

$107 \mathrm{Vgl}$. für eine Betonung dieser Faktoren etwa ROBERT I. MOORE, The First European Revolution, c. 970-1215, Oxford 2000 .

108 Vgl. systematisierend NiKOLAS JASPERT, Contacts between the Major Religious Traditions during their Expansion. An Introduction, in: KRECH - STEINICKE (Hgg.), Dynamics in the History of Religion (wie Anm. 9) S. 156-176. 
regionaler Verdichtung ${ }^{109}$-, bleibt zunächst offen. Das mag nun in der Soziologie und Geschichtswissenschaft der Gegenwart vielen ungenügend erscheinen, und es scheint aus der hier verfolgten Perspektive tatsächlich äußerst wünschenswert, weiter über eine differenzierungstheoretische Rahmung historischer Verläufe nachzudenken. Abschließend sollte daher noch gefragt werden, ob nicht mit dem an Niklas Luhmann ausgerichteten systemtheoretischen Verlaufsmodell, das ja auch Detlef Pollack adaptiert, eine sinnvollere Alternative gegeben ist?

Aus der hier verfolgten Perspektive - selbstverständlich nur eine unter vielen scheint dies aus mehreren Gründen nicht der Fall zu sein. Luhmann bietet zwar wie so oft äußerst interessante Anregungen. Sein historisches Verlaufsmodell gesellschaftlicher Differenzierungsformen dürfte allerdings mittlerweile einer der problematischsten Teile seines Gesamtwerks sein ${ }^{110}$.

In erster Linie ist die historische Forschung, auf die Luhmann sich stützte, mittlerweile zu großen Teilen veraltet. Zwar diagnostizieren seine Überlegungen an einigen Kernbereichen historischer Differenzierungsprozesse, etwa zum Wandel sozialer Ordnungen in der Frühen Neuzeit, tatsächlich wichtige Veränderungen und bieten Anknüpfungspunkte für die historische Arbeit ${ }^{111}$. Doch hat Luhmann seine historischen Überlegungen so stark auf älteren, selbst modernisierungstheoretisch beeinflussten historischen Arbeiten aufgebaut, dass das ältere Bild eines 'Rise of the West' seinem Modell fest und offenbar fast unveränderlich eingeschrieben ist. Man könnte zwar vielleicht auch eine systemtheoretisch ausgerichtete Geschichte unterschiedlicher regionaler Differenzierungsschübe des mittelalterlichen Europa schreiben. Doch müsste man meiner Ansicht nach mehr oder weniger bei Null anfangen und würde Luhmanns historisch bereits sehr stark spezifiziertes Modell dabei bis zur Unkenntlichkeit entstellen. Er beschreibt die Entwicklung gesellschaftlicher Differenzierung letztlich als Geschichte eines übergreifenden historischen Prozesses, der von der vormodernen zur modernen Gesellschaft führt. Um neueren Forschungsergebnissen gerecht zu werden, müsste man diese Geschichte mit einem Überblick über verschiedene, nebeneinander ablaufende oder teils miteinander verbundene regionale Prozesse ersetzen, die jeweils in mehr als die beiden historischen Zustände 'vormodern' und 'modern' unterteilt werden können.

Für weitere Überlegungen muss man zunächst einmal zwei Ebenen in Luhmanns Verlaufsmodell historischer Differenzierungsformen unterscheiden, die Ebene der

\footnotetext{
109 Ein solches Modell müsste nicht nur auf transkulturelle und überregionale, sondern auch auf innereuropäische und lokale Verdichtung bezogen sein - vgl. etwa PETER MORAW, Von offener Verfassung zu gestalteter Verdichtung. Das Reich im späten Mittelalter 1250 bis 1490 (Propyläen Geschichte Deutschlands 3) Frankfurt 1989.

${ }^{110} \mathrm{Vgl}$. mit Zusammenfassung von Kritikpunkten ansonsten ARMIN NASSEHI, Die Theorie funktionaler Differenzierung im Horizont ihrer Kritik, in: Zeitschrift für Soziologie 33/2, 2004, S. 98-118.

$111 \mathrm{Vgl}$. für produktive Operationalisierungen und Verknüpfung mit historischen Forschungsfragen etwa ANDrÉ Krischer - Barbara StOllberg-Rilinger (Hgg.), Herstellung und Darstellung von Entscheidungen. Verfahren, Verwalten und Verhandeln in der Vormoderne (ZHF Beihefte 44) Berlin 2010 .
} 
gesellschaftlichen Teilbereiche und die Ebene der Gesamtgesellschaft. Luhmann beschreibt historisch zunächst verschiedene Prozesse der Ausdifferenzierung gesellschaftlicher Teilbereiche, die sich seinem Modell gemäß in der Moderne zu operativ geschlossenen gesellschaftlichen Funktionssystemen entwickeln ${ }^{112}$. Sie stabilisieren sich auf der Basis eines bestimmten Codes (z. B. 'Recht'/ 'Unrecht' im Recht), mit dem sie sich von ihrer der Umwelt abgrenzen und fortan autopoietisch reproduzieren ${ }^{113}$. Die gesellschaftlichen Funktionssysteme regeln dabei nach Luhmann die Stabilität ihres Codes selbst, ähnlich wie auch die Definition und Grenzen der Bourdieuschen Felder von innen geregelt werden.

Luhmann setzt dabei nur überindividuelle Strukturbildungen durch Evolution und keine Akteursperspektiven an. Dies bewirkt, dass seine Überlegungen nicht ohne weiteres in die akteursorientierte historische Arbeit übernommen werden können, sondern zunächst 'übersetzt' werden müssen. Doch setzt Luhmann wie Bourdieu oder Weber langfristige historische Prozesse der Autonomisierung der gesellschaftlichen Teilbereiche an. Der Entstehung des Funktionssystems Recht an der Wende zur Moderne geht für Luhmann beispielsweise eine langgezogene, seit der Antike vorbereitete Ausdifferenzierung des Rechts voran, die den späteren evolutiven Schritt vorbereitet. Insofern lassen sich Luhmanns Annahmen durchaus mit historischen Befunden zur graduellen Entstehung bestimmter Formen des Rechts, der Religion und anderer Bereiche verknüpfen. Er hat häufig sehr interessante Beobachtungen zur Verknüpfung bestimmter Evolutionsmechanismen gemacht, etwa zur Verbreitung normativer Erwartungen über Schriftkultur und zur Entstehung eines professionellen Juristenstands als Voraussetzung der Entstehung übergreifender Rechtsstrukturen. Doch kann auch er nicht über das hinausgreifen, was ihm an historischen Forschungen vorlag. Da sein Interesse fast ausschließlich auf die historische Autonomisierung gesellschaftlicher Funktionssysteme gerichtet ist, hat er zudem keine ausführlichen Aussagen $\mathrm{zu}$ möglichen Autonomieverlusten gesellschaftlicher Teilbereiche gemacht.

Als weitere Ebene seines historischen Modells setzt Luhmann allerdings noch weitere Prozesse an, diesmal nicht auf der Ebene der gesellschaftlichen Teilbereiche, sondern auf der Ebene der Gesamtgesellschaft. Sie bringen eine fast unauflösliche Teleologie in seine historischen Überlegungen: Um sich von älteren Vorstellungen einer gleichmäßigen gesellschaftlichen Differenzierung abzugrenzen und die moderne Gesellschaft als eigenen, nicht mit der Vormoderne vergleichbaren Typ zu bestimmen, legt Luhmann ein Stufenmodell steigender sozialer Komplexität vor.

\footnotetext{
112 Vgl. Claudio Baraldi, Art. '(Aus-)Differenzierung', in: GLU (wie Anm. 6) S. 26-29; als Beispiel vgl. etwa NikLas LuHManN, Ausdifferenzierung des Rechts. Beiträge zur Rechtssoziologie und Rechtstheorie, Frankfurt a. M. 1981; DERS., Die Religion der Gesellschaft, hg. von ANDRÉ KIESERLING, Frankfurt a. M. 2000, Kap. 5: Die Ausdifferenzierung religiöser Kommunikation, S. $187-$ 225.

113 Das moderne Rechtssystem bearbeitet also nur noch Kommunikation, die dem Code 'Recht'/ Unrecht' folgt. Vgl. ElEnA Esposito, Art. 'Code', in: GLU (wie Anm. 6) S. 33-37; KNEER, Differenzierung (wie Anm. 30) S. 145-157.
} 
Dieses Modell ordnet historische Gesellschaftstypen nach ihrer „primären“ Differenzierungsform ${ }^{114}$. Wesentlich ist für Luhmann die Änderung des primären Differenzierungsprinzips von segmentärer $\mathrm{zu}$ stratifizierter $\mathrm{zu}$ funktionaler Differenzierung. Diesen drei Stufen ordnet er in etwa primitive Stammesgesellschaften, erste Hochkulturen wie das christlich-lateinische Mittelalter und schließlich moderne Gesellschaften $\mathrm{zu}^{115}$. Die gesellschaftliche Integration erfolgt in segmentären Gesellschaften primär über die Zugehörigkeit zu regionalen Segmenten wie Stämmen oder Familien. In einer primär stratifizierten Gesellschaft wird die Gesellschaft als Rang- oder Ständeordnung gedacht. In der primär funktional differenzierten Gesellschaft verdrängen jedoch die Eigenlogiken der Funktionssysteme ältere segmentäre und stratifizierte Gliederungen.

Der Vorteil der modernen gesellschaftlichen Integration liegt für Luhmann in der resultierenden Systemautonomie, die heutigen freiheitlichen und egalitären Wertmaßstäben entgegenkommt ${ }^{116}$ : Kurz gesagt, soll Recht in der modernen Gesellschaft nicht nach politischem Ansehen der Person (oder regional unterschiedlich) gesprochen werden. Was schön ist, soll nicht die Religion entscheiden, und wissenschaftliche Wahrheit soll man nicht mit Geld kaufen können. Die gesellschaftlichen Funktionssysteme hängen zwar in Luhmanns Modell durch sogenannte strukturelle Kopplung und Interpenetration ${ }^{117}$ zusammen, doch determinieren sie sich nicht gegenseitig, sondern regulieren sich nur.

In der historischen Operationalisierung dieses Modells ergeben sich jedoch sogleich Kritikpunkte. Der erste Punkt betrifft die Verzerrung historischer Entwicklungen, die durch Luhmanns offensichtlich idealtypisches Stufenmodell entsteht. Dies wurde bereits von Oexle und anderen Kritikern geäußert und von Pollack aufgenommen. Auch Luhmann selbst hat der Kritik letztlich bereits nachgegeben 118: Obwohl er eine endgültige Umstellung auf primär funktionale Differenzierung erst am Ende der Frühen Neuzeit ansetzt, ist die funktionale Differenzierung verschiedener Bereiche seiner Ansicht nach bereits früher vorhanden.

Dies spielt für Luhmanns Theoriebildung freilich keine Rolle, da es ihm in seinem Verlaufsmodell (anders als in seinen Überlegungen zur graduellen Ausdifferenzierung verschiedener Bereiche) nicht um die gesellschaftliche Differenzierung allgemein, sondern um die „primäre“ Form gesellschaftlicher Differenzierung geht. Die Überlegung Pollacks, dass die zunehmende Abgrenzung von geistlicher und weltlicher Herrschaft im Mittelalter als Emergenz funktionaler

114 Vgl. NiKLas LuHManN, Die Gesellschaft der Gesellschaft, Frankfurt a. M. 1997, S. 609-617.

115 Genauer wiedergegeben, setzt Luhmann noch eine Übergangsstufe von Zentrum-PeripherieDifferenzierung zwischen primär segmentären und primär stratifizierten Gesellschaften an, vgl. LUhmanN, Die Gesellschaft (wie Anm. 114) S. 613; Claudio Baraldi, Art. 'Gesellschaftsdifferenzierung', in: GLU (wie Anm. 6) S. 65-71.

116 Vgl. KNEER, Differenzierung (wie Anm. 30) S. 151-157.

117 Vgl. Elena Esposito, Art. 'Interpenetration', in: GLU (wie Anm. 6) S. 85-88; Dies., Art. 'Strukturelle Kopplung', ebd. S. 186-189.

$118 \mathrm{Vgl}$. oben bei Anm. 1. 
Differenzierung aufgefasst werden könnte, erscheint deswegen theorieimmanent problematisch: Eine graduell stärker werdende Ausdifferenzierung von Politik und Recht nimmt Luhmann für die Vormoderne sowieso an. Als Emergenz im Sinne der operativen Schließung von Funktionssystemen oder im Sinne des Übergangs zu primär funktionaler gesellschaftlicher Differenzierung erscheint dies jedoch nicht. Ein „Primat“ funktionaler Differenzierung wäre erst gegeben, wenn segmentäre und stratifizierende Differenzierung verdrängt sind ${ }^{119}$.

Diese Prozesse können jedoch in Luhmanns Verlaufsschema, das insgesamt auf die Weltgesellschaft bezogen ist ${ }^{120}$, definitionsgemäß erst mit der globalisierten Moderne zum Abschluss kommen. Der zunehmende Bezug verschiedener europäischer Mächte auf den Papst seit dem Hochmittelalter erscheint zwar als partielle Überwindung segmentärer Differenzierung. Doch ist klar, dass das mittelalterliche Europa, seine unmittelbare Nachbarschaft in Mittelmeerraum, Nahem Osten und Afrika sowie schließlich die weiteren Erdteile im Verlauf des Mittelalters noch keineswegs abschließend zusammengewachsen waren. Weiterhin ändern die Auseinandersetzungen zwischen Päpsten und Königen nichts an der Akzeptanz von Stratifizierung als gesellschaftlichem Ordnungsprinzip - die gesellschaftliche Stratifizierung müsste man mit Luhmann im Hochmittelalter sogar noch als entstehend ansehen, was auch historisch durchaus Sinn macht. Funktionale Differenzierung kann also, theorieimmanent gesehen, im Hochmittelalter schon per definitionem nicht primäres gesellschaftliches Strukturprinzip sein.

Das Modell Luhmanns erweist sich in diesem Punkt somit als äußerst schwerfällig: Es verknüpft drei verschiedenartige, jeweils äußerst voraussetzungsreiche historische Prozesse, denn regionale Verflechtung, funktionale Differenzierung und Veränderungen der gesellschaftlichen Schichtung werden in einem historischen Verlaufsschema aneinander gekoppelt. Man kann in Luhmanns Mittelalter schon deswegen immer nur 'Vorläufer' moderner Entwicklungen postulieren, da er für die Moderne eben eine völlige Verdrängung der stratifizierten Ordnung ansetzt, und zwar weltweit.

Daraus ergeben sich nun diverse Kritikpunkte: Da Luhmann selbst ja verschiedene Vorläufer- und Übergangsphänomene ansetzt, müsste man sein historisches Verlaufsmodell eigentlich um Übergangsepochen erweitern. Dies hat er teils selbst mit dem Postulat einer anfänglichen Zentrum-Peripherie-Differenzierung zwischen den Phasen der primär segmentären und der primär stratifizierten Gesellschaft getan ${ }^{121}$. Doch müsste man schon bei grobem Hinsehen anstelle dreier Idealtypen gesellschaftlicher Differenzierung eigentlich zwei Idealtypen von Übergangsgesellschaften postulieren: Nach einer Phase segmentärer Differenzierung wäre eine Übergangsepoche teils primär segmentärer, teils primär stratifizierter Gesellschaft anzusetzen. Sie müsste sich wohl von der Antike bis ins Hochmittelalter

119 Vgl. LuHManN, Die Gesellschaft (wie Anm. 114) S. 612-613.

${ }^{120}$ Vgl. Claudio BARALDI, Art. 'Gesellschaft', in: GLU (wie Anm. 6) S. 63-64.

121 Vgl. Luhmann, Die Gesellschaft (wie Anm. 114) S. 612. 
hinziehen. Daran müsste sich eine Übergangsepoche der teils primär stratifizierten, teils primär funktional differenzierten Gesellschaft anschließen. Sie dürfte historisch etwa zwischen dem Hochmittelalter und der Hochmoderne zu verorten sein - wenn sie überhaupt endet - darauf wird gleich noch einmal zurückzukommen sein.

Das Luhmannsche Stufenmodell wirkt aber schon wegen der postulierten Übergänge eher als Behinderung denn als möglicher Fragerahmen für weitere historische Forschungen. Nicht nur können die postulierten Übergänge chronologisch nicht genauer festgemacht werden, da dies eine Vielzahl von regionalen Parallelerzählungen erfordern würde. Das vorgelegte Stufenmodell gibt zudem für die historische Arbeit zu enge Frageraster vor. Um Luhmann nachzuarbeiten, müsste man, theorieimmanent gedacht, erneut fragen, wo in Antike und Frühmittelalter Übergänge von segmentärer zu stratifizierter gesellschaftlicher Differenzierung auftreten. Doch wissen wir ja bereits, dass es auch in dieser Zeit Verschiebungen in der funktionalen Differenzierung gibt, die von solchen Fragen dann außen vor gelassen würden. Umgekehrt gibt es auch zwischen Hochmittelalter und Hochmoderne äußerst wichtige regionale Verflechtungsprozesse, die man übersehen würde, wenn man nur nach Verschiebungen von stratifizierender zu funktionaler Differenzierung fragt. Mehr Sinn macht es offensichtlich, die von Luhmann gekoppelten drei Prozesse jeweils einzeln zu verfolgen beziehungsweise an spezifischen historischen Fallstudien in sinnvoller Weise miteinander zu verknüpfen. Doch das ist wiederum einfacher mit der Feldtheorie Bourdieus oder in anderen Rahmungen zu haben.

$\mathrm{Da}$ mittlerweile an Luhmanns Vorstellung einer flächendeckenden gesellschaftlichen Inklusion durch die Funktionssysteme einige Kritik geübt worden ist, könnte man zudem seine gesamte Abgrenzung der Moderne in Frage stellen. Man könnte etwa überlegen, ob die moderne Gesellschaft nicht ebenfalls eine teils stratifizierte, teils funktional differenzierte Gesellschaft ist und sich somit nur graduell von vormodernen Gesellschaften unterscheidet ${ }^{122}$. Unterschiede in gesellschaftlichem Rang und Status gibt es ja auch heute noch, zumal in der Weltgesellschaft. Luhmann geht zwar selbst davon aus, dass auch innerhalb primär funktional differenzierter Gesellschaften selbstverständlich Rang- und Standesunterschiede gegeben sein können. Er sieht aber die primär funktionale Differenzierung von ihnen nicht gefährdet.

Doch worin soll diese „primär“ funktionale Differenzierung dann bestehen? Status und sozioökonomische Stellung in den Bereichen Politik und Wirtschaft sollten in der modernen Gesellschaft nicht mehr in der Lage sein, die Operationen anderer Funktionssysteme zu „determinieren“, da sie lediglich deren Umwelt sind ${ }^{123}$. Doch was heißt „determinieren“? Dass sie sie beeinflussen, da strukturelle Kopplungen zwischen den Funktionssystemen gegeben sind, sieht Luhmann ja ganz ausdrücklich

${ }_{122}$ Vgl. die kritische Diskussion bei NASSEHI, Die Theorie (wie Anm. 110) S. 110-115.

123 So z. B. LuHmann, Die Gesellschaft (wie Anm. 114) S. 790. 
als gegeben an. Das genaue Funktionieren des Leistungsaustauschs zwischen den Systemen bleibt allerdings bei ihm etwas undeutlich, da er seine Energie vor allem auf eine historisch argumentierende Herleitung der Autonomie der Funktionssysteme verwandt hat. Was dagegen fehlt, ist eine systematische Betrachtung ihrer Verknüpfung, so wie sie Bourdieu mit Überlegungen zur Autonomie der Felder und seiner Theorie verschiedener Kapitalsorten vorgelegt hat - also der Überlegung, dass soziale Beziehungen nach historisch kontingenten Umwandlungsregeln in wirtschaftlichen Gewinn umgesetzt werden können, symbolisches Kapital aus dem Bereich des wissenschaftlichen Feldes den Akteuren auch auf dem politischen Feld hilft etc. ${ }^{124}$ Dieser Punkt wiegt umso schwerer, als man Luhmann auch vorgeworfen hat, zu stark auf die Trennung der Funktionssysteme auf der theoretischen Ebene der Gesamtgesellschaft zu fokussieren, während die konkrete Realisierung von Kommunikationen auf der Ebene direkter Interaktion eine starke praktische Verknüpfung der Funktionsbereiche zeigt ${ }^{125}$.

Wenn man also zu fragen beginnt, wo nach historisch neuestem Stand angesichts der komplexen Verknüpfungen gesellschaftlicher Teilbereiche mit Luhmann ein Übergang von einer primär stratifizierten zu einer primär funktional differenzierten Gesellschaft tatsächlich postuliert werden könnte, wird deutlich, dass er in der Praxis an hunderten von regionalen Ansatzpunkten und tausenden von sozialen Praktiken festgemacht werden müsste. Wirtschaft, Politik, Recht, Wissenschaft, Religion kreuzen sich ja im Alltag ständig, können jedoch regional und historisch sehr unterschiedliche Ausformungen annehmen. Die derzeit wieder heiß diskutierten Kernbereiche dieser Verschränkungen, etwa die subjektiven Freiheitsrechte ${ }^{126}$, bieten sicherlich Ansatzpunkte, um besonders wichtige Umstellungen zu diskutieren. Zentral scheint die Zurückdrängung stratifizierender Elemente in den Funktionsbereichen Recht und Politik. Doch kann man sie auch erforschen, ohne die systemtheoretische Differenzierungstheorie der nötigen historischen Gesamtüberholung zu unterwerfen.

Denn gerade für die historische Erforschung von Veränderungen gesellschaftlicher Differenzierung scheint das Luhmannsche Modell schließlich noch einen besonderen Fallstrick parat zu halten: Obwohl das theorieimmanent vermutlich nicht beabsichtigt ist, scheint es doch so, als ob das systemtheoretische Entwicklungsmodell mit seiner Zweiteilung in eine vormoderne Phase diffuser gesellschaftlicher Differenzierungen und eine moderne Phase gesellschaftlicher

\footnotetext{
124 Vgl. knapp Pierre BOURdieu, Ökonomisches Kapital, kulturelles Kapital, soziales Kapital, in: ReInHard Kreckel (Hg.), Soziale Ungleichheiten (Soziale Welt. Sonderband 2) Göttingen 1983, S. 183-198.

125 Vgl. NASSEHI, Die Theorie (wie Anm. 110) S. 105-110.

126 Vgl. zu den subjektiven Rechten etwa auch NIKLAS LUHMANN, Subjektive Rechte: Zum Umbau des Rechtsbewusstseins für die moderne Gesellschaft, in: DERS., Gesellschaftsstruktur und Semantik, Studien zur Wissenssoziologie der modernen Gesellschaft, 2, Frankfurt a. M. 1981, S. 105-195; MATTHIAS KOENIG, Recht auf Religionsfreiheit - ein neuzeitliches Differenzierungsmuster und seine Entstehung, in: GABRIEL - GÄRTNER - POLLACK (Hgg.), Umstrittene Differenzierung (wie Anm. 4) S. 293-312.
} 
Integration über autopoietisch reproduzierte Funktionssysteme zweierlei Terminologien für die Untersuchung von Differenzierung vorgibt. In der vormodernen Phase ist von „Ausdifferenzierung“ die Rede, und es entsteht der Eindruck einer historisch wandelbaren gegenseitigen Differenzierung verschiedener Bereiche. Eigentlich müsste Luhmann für diese Phase ähnlich wie Bourdieu unterschiedliche Grade der Autonomie der gesellschaftlichen Bereiche ansetzen. Für die fertig ausdifferenzierten, operativ geschlossenen und aus sich selbst heraus reproduzierten Funktionssysteme nimmt Luhmann jedoch „Autonomie“ an, die aber mit struktureller Koppelung an andere Funktionssysteme einhergeht. Veränderungen in der Verknüpfung zwischen Bereichen wie Religion und Politik erscheinen somit in der Vormoderne als Veränderungen eines Autonomiegrades (soweit Luhmann diesen untersucht). In der Moderne erscheinen sie aber lediglich als unterschiedlich ausgeprägte strukturelle Koppelung. Es bleibt eigentlich unklar, inwiefern sich der Grad der Autonomie der Funktionssysteme dann noch ändern kann - oder anders formuliert, ob die funktionale Differenzierung sich historisch noch ändert.

Am Beispiel der Verknüpfung von Religion und Politik in der Herrscherlegitimation wurde hier nun deutlich, dass es in Mittelalter und Moderne um vergleichbare Phänomene des Ressourcenaustauschs geht: In den Kulturen des europäischen Mittelalters mussten Herrscher zumeist religiöse Qualifikationen nachweisen, und der Bereich des Religiösen leistete somit Orientierungshilfe bei der internen Organisation des Politischen. In der Gegenwart könnte man unter den veränderten Bedingungen einer weltanschaulich neutralen Politik, wie oben angedeutet, ähnliche Orientierungsfunktionen religiöser oder profan-moralischer Werte postulieren. Für die Zeit dazwischen lässt sich eine wechselvolle, doch im Prinzip allmählich pluralisierte Verknüpfung nachvollziehen. Doch nach Luhmanns Modell spielen die beobachtbaren graduellen Unterschiede nur eine untergeordnete Rolle. Bei ihm wird die mittelalterliche Verschränkung von Religion und Politik stattdessen von einer prinzipiellen Verknüpfung der beiden Bereiche geprägt, die moderne jedoch von prinzipieller Autonomie. Wiewohl es durchaus plausibel scheint, historisch unterschiedliche Grade der Autonomie von Religion und Politik anzusetzen, ist doch nicht einzusehen, warum die gesamte Vormoderne vom einen, die gesamte Moderne ihrem Wesen nach vom anderen Prinzip dominiert sein soll. Setzt man jedoch graduelle Unterschiede an, die theoretisch in Luhmanns Modell durchaus ihren Platz haben könnten, wird sofort wieder das gesamte Verlaufsmodell fraglich. Warum so und nicht anders?

Angesichts dieser Aporien wird deutlich, dass Luhmanns Differenzierungstheorie eine brillante gesellschaftliche Selbstbeschreibung des späten 20. Jahrhunderts sein mag, als forschungspragmatische Rahmung aber wenig einladend ist: Sie ist (anders als viele andere Aspekte seines Werks) wenig geeignet, weitere historische Arbeit anzuregen, spezifische Fragen zu generieren oder gar epochenübergreifende Orientierungen $\mathrm{zu}$ bieten. Sie ist historisch viel $\mathrm{zu}$ stark spezifiziert, und zwar auf der Basis eines selbst schon historischen, 
modernisierungstheoretischen Modells gesellschaftlicher Differenzierung. Das Feldmodell Bourdieus ist als Arbeitsgrundlage gerade wegen seiner historischen Offenheit brauchbarer. Es kann eigentlich nur eines nicht in zufriedenstellender Weise leisten, nämlich die von Luhmann so häufig beschworene und mit seinem historischen Modell auch angebotene Komplexitätsreduktion, die zugleich der Moderne das Angebot einer fundierenden Großerzählung macht. Bourdieu kann kein neues, griffiges und eingängiges Modell der Epocheneinteilung vorlegen, das im Bewusstsein der breiteren Öffentlichkeit die Vorstellung einer Modern-Werdung, eines mittelalterlichen 'Rise of the West' oder gar der alten Burckhardtschen Renaissance verdrängen könnte. Das wird die historische Forschung selbst tun müssen - doch könnte eine ergebnisoffen operationalisierte Differenzierungstheorie dabei eine wesentliche Diskussionsgrundlage bieten.

\section{SCHLUSSÜBERLEGUNGEN: KONJUNKTUREN DES RELIGIÖSEN}

Abschließend muss es vorerst ausreichen, einen zentralen Gedanken für eine historisch operationalisierte Theorie gesellschaftlicher Differenzierung von Religion hervorzuheben: Die Frage nach dem Verhältnis von Religion gegenüber anderen Bereichen zeigt historisch ein bewegtes Bild. Da sich die mittelalterliche genauso wie die moderne Welt in ständigen Prozessen kultureller Ver- und Entflechtung befand, begegnet uns Religion nicht in einer linearen Entwicklung, sondern in historischer Dynamik. Wir sehen Konjunkturen des Religiösen, die als Grenzarbeiten am religiösen Feld oder als Verlagerungen des Heiligen erscheinen, als „Migrations of the Holy“, wie die britische Frühneuzeithistorikerin Alexandra Walsham kürzlich formuliert hat ${ }^{127}$. Zwar dürfte die Bedeutung von Religion seit dem Mittelalter stark abgenommen haben, insgesamt wie in ihrer Rolle für andere gesellschaftliche Bereiche. An den Schnittstellen zwischen Religion und anderen Funktionsbereichen sind jedoch auch heute noch Veränderungen und konfliktgetriebene Neuerungen zu beobachten, und sie haben weit zurückreichende Parallelen.

Ein Nachweis, dass ausdifferenzierte Religion oder funktionale Differenzierung im Mittelalter ihren Ursprung genommen hätten, scheint mir daher nicht weit genug zu gehen. Die Annahme wiederholter Konjunkturen des Religiösen will stattdessen unterstreichen, dass die Bereiche des Religiösen und der gesellschaftlichen Differenzierung immer schon dynamisch waren. Das Mittelalter ist in diesem Punkt weder Ursprung noch Anderes der Moderne, sondern bietet Parallelen und Vergleichsfälle zur Gegenwart. Man könnte, wie zuletzt der Reformationshistoriker Berndt Hamm vorgeschlagen hat, tatsächlich im Moment gut ohne die Vorstellung von Epochenbrüchen auskommen ${ }^{128}$. Wenn man den Fokus auf historische

\footnotetext{
127 Vgl. Walsham, Migrations of the Holy (wie Anm. 15); Dies., The Reformation (wie Anm. 15) S. 517, im Anschluss an John Bossy. Ähnlich JOAS, Gefährliche Prozessbegriffe (wie Anm. 9) S. 619.

${ }^{128}$ Vgl. BERNDT HAMM, Abschied vom Epochendenken in der Reformationsforschung. Ein Plädoyer, in: Zeitschrift für Historische Forschung 39/3, 2012, S. 373-411.
} 
Transformationen von Religion legt, empfehlen sich daher historische Verlaufsannahmen, die multilineare und reversible Prozesse beschreiben können. Wie ausführlich diskutiert, bietet sich die historisch weniger ausgearbeitete Feldtheorie Bourdieus daher stärker als theoretischer Rahmen an als die Systemtheorie Luhmanns, die zudem verschiedene Probleme mit sich bringt.

Wie genau wir die kurz- und mittelfristigen Transformationen innerhalb eines übergreifenden feldtheoretischen oder sonstigen Rahmens zu denken hätten, wird im Moment jedoch noch intensiv diskutiert. Schon für die Konzeptionalisierung übergreifender historischer Prozesse wird von verschiedenen Seiten mit Überlegungen zu historischen „Wellen“, „Zyklen“, „Spiralen“ oder wiederkehrenden „Dialogiken“ experimentiert ${ }^{129}$. Für den genaueren Zugriff auf Phänomene des Religiösen und ihre interne Differenzierung sowie auf Verschränkungen des religiösen Feldes mit anderen Feldern stehen ebenfalls Ansatzpunkte bereit ${ }^{130}$. Es zeichnen sich insbesondere rahmende Metaphern ab, durch die sich die linearen Fragerahmen und „gefährlichen Prozessbegriffe“ des alten Freisetzungsparadigmas erheblich dynamisieren lassen dürften. Darunter sind etwa die Fragen nach Sakralisierungen und Entsakralisierungen, nach Schüben kultureller Pluralisierung und Vereindeutigung, nach Divergenzen und Konvergenzen, nach Grenzarbeiten oder Ko-Evolution zwischen Feldern. Auch wegen dieser vielfältigen Operationalisierungsmöglichkeiten erscheint das Thema der Differenzierungstheorie als Ansatzpunkt für weitere Diskussion. Es ist schlicht so grundlegend, dass es sich als Vermittlungs- und Verständigungsebene für Soziologie, Geschichte und andere Disziplinen anbietet.

Für die Mediävistik scheint die intensivierte Diskussion dieser Themen äußerst wichtig: Wenn sie in der Dynamisierung der älteren Großparadigmen nicht außen vor bleiben soll, hat die Mittelalterforschung im Moment sozusagen eine Bringschuld. Es wird in unserem Fach intensiv und auf hohem Niveau an Fragestellungen der Religionsgeschichte geforscht - und schon das traditionelle, abendländisch gedachte Mittelalter umfasst zehn Jahrhunderte äußerst bewegter Geschichte. Doch von deren Dynamik kommt offensichtlich in der Gegenwartssoziologie zu wenig an. Die vorliegenden älteren Überblicksdarstellungen bleiben noch $\mathrm{zu}$ stark dem älteren Modernisierungsparadigma verhaftet, und in neueren Handbüchern scheint das Mittelalter oftmals zu wenig vertreten ${ }^{131}$.

Von der Perspektive Detlef Pollacks, der wie andere Soziologen schon deswegen nur auf ein modernisierungstheoretisch gefiltertes Mittelalter zugreifen kann, weicht die meinige daher sehr erheblich ab. Doch betrifft der Dissens weder die Bedeutung

\footnotetext{
${ }^{129}$ Vgl. WALsham, Migrations of the Holy (wie Anm. 15) Kap. 3; OTTO Gerhard OeXle, Kommentar, in: GABRIEL - GÄRTNER - POLLACK (Hgg.), Umstrittene Säkularisierung (wie Anm. 4) S. 176-188, hier S. 179-180 mit Verweis auf Eugenio Garins Konzept von 'Dialogiken'.

${ }_{130} \mathrm{Vgl}$. für verschiedene methodische Dimensionen die Literatur in Anm. 11 oben sowie KRECH, Dynamics in the History of Religion (wie Anm. 85), und die Beiträge in KIPPENBERG - RÜPKE - VON STUCKRAD (Hgg.), Europäische Religionsgeschichte (wie Anm. 9).

131 Vgl. etwa die wenigen Mittelalterkapitel in KIPPENBERG - RÜPKE - VON STUCKRAD (Hgg.), Europäische Religionsgeschichte (wie Anm. 9).
} 
der Gesamtthematik der Differenzierung noch den akteursorientierten methodischen Zugriff, sondern lediglich die Rahmung historischen Forschens und die Sichtweise auf die europäische Vormoderne. Unsere Perspektiven unterscheiden sich wohl nicht zuletzt im Verständnis der Gegenwart und im Verständnis dessen, was die Erforschung des Mittelalters zu ihr beitragen kann. Detlef Pollack sieht das christlicheuropäische Mittelalter ganz zu Recht als wichtige Grundlage der westlichen Moderne. Mir scheint, dass ein dynamischer gedachtes Mittelalter darüber hinaus gerade in seiner Vielfalt und Widersprüchlichkeit viel mit der globalen Gegenwart gemeinsam hat. 